\title{
OPEN Subtoxic cell responses to silica particles with different size and shape
}

\author{
Markus Kersting ${ }^{1,5}$, Mateusz Olejnik ${ }^{2,5}$, Nina Rosenkranz ${ }^{3}$, Kateryna Loza², Marina Breisch ${ }^{1}$, \\ Alexander Rostek ${ }^{2}$, Götz Westphal ${ }^{3}$, Jürgen Bünger ${ }^{3}$, Nadine Ziegler ${ }^{4}$, Alfred Ludwig ${ }^{4}$, \\ Manfred Köller ${ }^{1}$, Christina Sengstock ${ }^{1 \bowtie}$ \& Matthias Epple ${ }^{2 \bowtie}$
}

Health risks from particles are a priority challenge to health protection at work. Despite the ubiquitous exposure to a wide range of particles and the many years of research in this field, there are fundamental unresolved questions regarding the prevention of particle-related respiratory diseases. Here, the highly relevant particulate material silicon dioxide was analyzed with emphasis on defined size and shape. Silica particles were prepared with different size and shape: Spheres (NS nanospheres $60 \mathrm{~nm}$; SMS submicrospheres $230 \mathrm{~nm}$; MS microspheres $430 \mathrm{~nm}$ ) and rods (SMR submicrorods with $d=125 \mathrm{~nm}, L=230 \mathrm{~nm}$; aspect ratio 1:1.8; MR microrods with $d=100 \mathrm{~nm}, L=600 \mathrm{~nm}$; aspect ratio 1:6). After an in-depth physicochemical characterization, their effects on NR8383 alveolar macrophages were investigated. The particles were $\mathrm{X}$-ray amorphous, well dispersed, and not agglomerated. Toxic effects were only observed at high concentrations, i.e. $\geq 200 \mu \mathrm{g} \mathrm{m}^{-1}$, with the microparticles showing a stronger significant effect on toxicity (MS $\approx M R>S M R \approx S M S \approx N S$ ) than the nanoparticles. Special attention was directed to effects in the subtoxic range (less than $50 \%$ cell death compared to untreated cells), i.e. below $100 \mathrm{\mu g} \mathrm{mL}^{-1}$ where chronic health effects may be expected. All particles were readily taken up by NR8383 cells within a few hours and mainly found associated with endolysosomes. At subtoxic levels, neither particle type induced strongly adverse effects, as probed by viability tests, detection of reactive oxygen species (ROS), protein microarrays, and cytokine release (IL-1 $\beta$, GDF-15, TNF- $\alpha$, CXCL1). In the particle-induced cell migration assay (PICMA) with leukocytes (dHL-60 cells) and in cytokine release assays, only small effects were seen. In conclusion, at subtoxic concentrations, where chronic health effects may be expected, neither size and nor shape of the synthesized chemically identical silica particles showed harmful cell-biological effects.

Silica is the oxide of silicon, i.e. $\mathrm{SiO}_{2}$. If prepared by wet-chemical synthesis, it is usually $\mathrm{X}$-ray amorphous and can be represented by the general formula $\mathrm{SiO}_{2} \cdot \mathrm{x} \mathrm{H}_{2} \mathrm{O}$ (amorphous silica or polysilicic acid). Several anhydrous and crystalline forms are also known, with quartz (stoichiometric $\mathrm{SiO}_{2}$ ) being the most prominent ${ }^{1}$. In combination with other metal oxides, crystalline silicates form the biggest part of the earth's crust, and are almost ubiquitous. Silica particles (usually in the X-ray amorphous form) have many applications, e.g. in food or consumer products, as well as in biomedicine for potential therapeutic applications like gene and protein delivery and optical imaging ${ }^{2-4}$. Due to favorable properties like colloidal and chemical stability, the possibility for a covalent surface modification, and a high specific surface area, the application cases for silica particles and silica-based materials have grown rapidly ${ }^{5-8}$. Still, the development and synthesis of silica particles with precisely controlled physicochemical properties like shape, particle size distribution, and surface charge are critical steps for their toxicological evaluation and also for their use for biomedical application ${ }^{7,9-17}$.

Silica (nano-)particles are also of high importance in food and consumer products ${ }^{1,18}$. Although silica is considered to be non-toxic after oral intake ${ }^{18}$, it can cause inflammatory effects after inhalation ${ }^{6,19-22}$. Continuously high levels of inhalative particle exposure, including silica, lead to a chronic inflammation of the lung,

\footnotetext{
${ }^{1}$ BG University Hospital Bergmannsheil, Surgical Research, Ruhr University Bochum, Bochum, Germany. ${ }^{2}$ Inorganic Chemistry and Center for Nanointegration Duisburg-Essen (CeNIDE), University of Duisburg-Essen, Essen, Germany. ${ }^{3}$ Institute for Prevention and Occupational Medicine of the German Social Accident Insurance, Institute of the Ruhr University Bochum (IPA), Bochum, Germany. ${ }^{4}$ Chair for Materials Discovery and Interfaces, Institute for Materials, Faculty of Mechanical Engineering, Ruhr University Bochum, Bochum, Germany. ${ }^{5}$ These authors contributed equally: Markus Kersting and Mateusz Olejnik. ${ }^{\square}$ email: christina.sengstock@ruhr-uni-bochum.de; matthias.epple@uni-due.de
} 


\begin{tabular}{|c|c|c|c|c|c|c|c|c|c|}
\hline & $\begin{array}{l}\text { Size by SEM/ } \\
\text { nm }\end{array}$ & $\begin{array}{l}\text { Size by DLS/ } \\
\text { nm }\end{array}$ & PDI from DLS & $\begin{array}{l}\text { Zeta potential } \\
\text { by DLS/mV }\end{array}$ & $\begin{array}{l}\text { Size by DLS/ } \\
\text { nm }\end{array}$ & PDI from DLS & $\begin{array}{l}\text { Zeta potential } \\
\text { by DLS/mV }\end{array}$ & \multirow{2}{*}{$\begin{array}{l}\text { Particle } \\
\text { number per g } \\
\text { solid }\end{array}$} & \multirow{2}{*}{$\begin{array}{l}\text { Specific surface } \\
\text { area/ } / \mathbf{m}^{2} \mathbf{g}^{-1}\end{array}$} \\
\hline & \multicolumn{4}{|c|}{ Unfunctionalized } & \multicolumn{3}{|c|}{ Coated with PEI } & & \\
\hline Nanospheres & 60 & 117 & 0.22 & -16 & 222 & 0.32 & +29 & $4.42 \times 10^{15}$ & 50 \\
\hline $\begin{array}{l}\text { Submicro- } \\
\text { spheres }\end{array}$ & 230 & 272 & 0.08 & -53 & 360 & 0.21 & +36 & $7.85 \times 10^{13}$ & 13 \\
\hline Submicrorods & $125 \cdot 230$ & 357 & 0.23 & -29 & 423 & 0.38 & +22 & $2.77 \times 10^{14}$ & 22 \\
\hline Microspheres & 430 & 519 & 0.15 & -28 & 582 & 0.19 & +39 & $1.20 \times 10^{13}$ & 7.0 \\
\hline Microrods & $100 \cdot 600$ & 439 & 0.32 & -22 & 564 & 0.45 & +28 & $1.06 \times 10^{14}$ & 21 \\
\hline
\end{tabular}

Table 1. Physicochemical characterization data of the silica particles, both unfunctionalized and coated with polyethyleneimine (PEI). All particles were completely X-ray amorphous. The particle numbers and the specific surface area were computed from the SEM particle size data. DLS was performed in water at $\mathrm{pH} 7$.

characterized by the accumulation of inflammatory cells, in particular alveolar macrophages and neutrophil granulocytes ${ }^{23}$. Chronic inflammation can lead to fatal lung dysfunction, including chronic obstructive pulmonary disease (COPD), fibrosis (such as silicosis and asbestosis), and cancer ${ }^{21,24-30}$. Crystalline silicon dioxide (like quartz) appears to be more harmful than amorphous silica, possibly due to its different surface nature and lower water content ${ }^{8,18,21,29,31}$.

Although there is extensive literature on the biological effects of silica particles, most studies are difficult to compare because of different particle properties like size, shape, charge or surface functionalization ${ }^{27,32}$. Usually, the cell types challenged with silica particles are also different which makes a comparison difficult ${ }^{14,18,27,33}$. Thus, there is no consensus about the different and potentially adverse biological effects of silica ${ }^{26}$. Furthermore, only few methods have been described for the preparation of monodisperse rod-shaped silica particles without templates or polymer additives, being present in well-dispersed and not agglomerated form.

Thus, our aim was to prepare silica particles with different shape (spheres and rods) and different size from nano- to microscale, but with identical surface chemistry. Five morphologically different but chemically uniform silica samples were synthesized and characterized, i.e. all parameters were kept constant except for particle size and shape. Special emphasis was laid on the inflammatory potential in the subtoxic concentration range (particle concentration which provoked less than $50 \%$ cell death compared to the untreated cell control) which is less frequently investigated, but may have strong effects in a persistent long-term exposition, e.g. promote a chronic inflammation. As the chemo-attraction of neutrophils is a key event in inflammation, the particle-induced migration of neutrophils is suggested as a functional and predictive in vitro model for the mechanistic investigation of a particle-induced inflammation of the lung ${ }^{34-36}$.

\section{Results}

The first synthesis of monodisperse spherical silica particles with a narrow size distribution was reported by Stöber et al..$^{37}$. Based on this method, many modifications to synthesize silica particles in the size range of $50 \mathrm{~nm}$ to $1 \mu \mathrm{m}$ by the hydrolysis of tetraethyl orthosilicate (TEOS) in the presence of ammonia have been published. Particle size and shape can be adjusted by the choice of additives ${ }^{5,9,38}$. We prepared spherical particles with three different diameters (denoted here as nanospheres NS: $60 \mathrm{~nm}$, submicrospheres SMS: $230 \mathrm{~nm}$, and microspheres MS: $430 \mathrm{~nm}$ ) by variations of the Stöber method $^{39}$. The particle size was controlled by changing the molar ratios of the reagents in the reaction mixture (TEOS, water and ammonia) and performing syntheses at different temperatures $\left(25^{\circ} \mathrm{C}, 47^{\circ} \mathrm{C}, 68^{\circ} \mathrm{C}\right)$. For the synthesis of rod-shaped silica particles with different lengths (denoted here as submicrorods SMR: $125 \mathrm{~nm} \cdot 230 \mathrm{~nm}$, and as microrods MR: $100 \mathrm{~nm} \cdot 600 \mathrm{~nm}$ ), the cationic surfactant $\mathrm{CTAB}$ was used to induce a rod-shaped growth of the particles by modification of the Stöber process using the soft-template strategy ${ }^{39,40}$. We classified the particles as "nano", "submicro", and "micro" for the sake of simplicity for the following discussion. For microscopic cell uptake studies, all synthesized silica particles were fluorescently labeled with fluorescein isothiocyanate-functionalized polyethyleneimine (PEI-FITC). All syntheses were multiply carried out and very robust in terms of reproducibility.

The particles were characterized by scanning electron microscopy (SEM), dynamic light scattering (DLS), UV/vis spectroscopy, infrared (IR) spectroscopy and X-ray powder diffraction (XRD). All physicochemical data are summarized in Table 1.

The size of the silica particles and their morphology were determined by SEM (Fig. 1). Scanning electron micrographs showed spherical and rod-like particles with a narrow particle size distribution. The corresponding histograms of the number-weighted particle diameters and lengths are shown in Fig. 2. From these data, geometric parameters and particle concentrations can be derived.

To investigate the colloidal stability and the particle size distribution, we performed DLS measurements (Fig. 3). The polydispersity index (PDI) was below 0.3 for all particles, indicating a low degree of agglomeration in the particle dispersions ${ }^{13}$. This is supported by the fact that the hydrodynamic diameter by DLS was only a little larger than the diameter of the solid core as determined by SEM. The zeta potential measurements at $\mathrm{pH}$ 7 in water showed that all unfunctionalized particles were negatively charged (due to deprotonation of surface silanol groups) whereas all PEI-coated particles carried a positive charge due to the cationic polyelectrolyte PEI.

X-ray powder diffraction showed that all silica particles were non-crystalline, i.e. fully amorphous (Fig. 3 ). Thus, we can exclude the presence of crystalline $\mathrm{SiO}_{2}$, i.e. the particles consist exclusively of hydrated silica in 

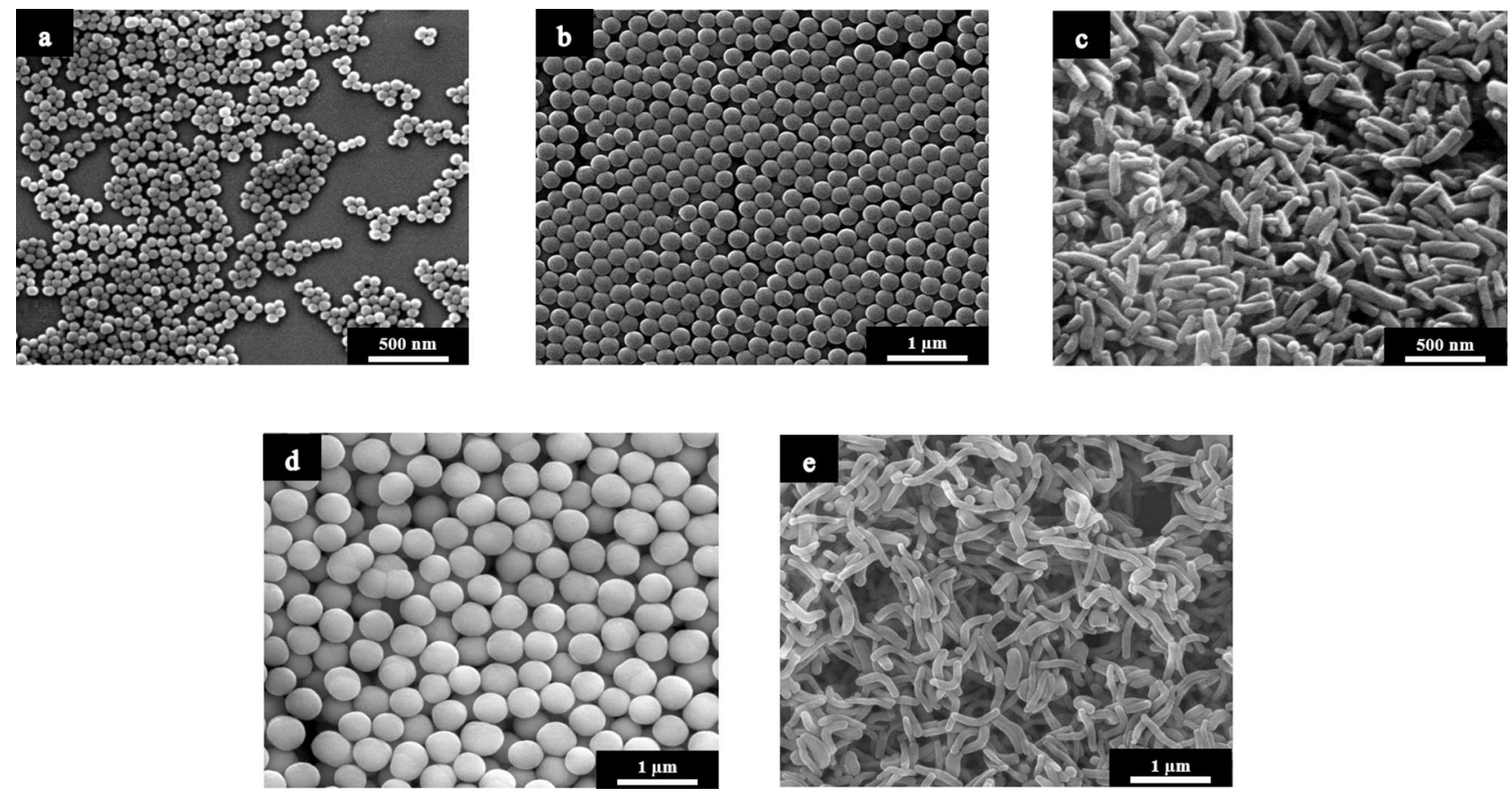

Figure 1. SEM images of unfunctionalized silica particles: Nanospheres (a), submicrospheres (b), submicrorods (c), microspheres (d), microrods (e).

the form of $\mathrm{SiO}_{2} \cdot \mathrm{x} \mathrm{H}_{2} \mathrm{O}$. The IR spectra showed characteristic $\mathrm{Si}-\mathrm{O}$ stretching bands at 1082 to $1114 \mathrm{~cm}^{-141}$. For rod-like particles, the complete removal of CTAB (a potentially cytotoxic synthesis additive) was confirmed by IR spectroscopy (absence of C-H bands). For PEI-FITC-labeled particles, the UV/vis spectrum showed the expected absorption band at $495 \mathrm{~nm}$ (FITC).

The cell-to-particle contact plays a strong role for the biological effects ${ }^{42,43}$. When it comes to contact with cells, the colloidal stability (sedimentation rate) is of prime importance. We have therefore used an in vitro sedimentation, diffusion and dosimetry model (ISDD) to estimate the particle precipitation and diffusion both in water and in cell culture media (Fig. 4) ${ }^{44}$. Due to their high density, the microparticles will sediment rapidly onto the cells, whereas the nanoparticles remain in dispersion for a much longer time. Table 2 summarizes the concentration data at the subtoxic concentration of $100 \mu \mathrm{g} \mathrm{mL} \mathrm{m}^{-1}$.

As typical cells of the immune system, NR8383 rat alveolar macrophages were used for cell culture experiments and incubated with silica particles in defined doses with different specific particle surface areas. These cells have also been proposed as models for particles to elucidate inhalation toxicity in in vitro assays ${ }^{32}$. The activity of particles in biological systems essentially depends on whether the particles can penetrate cells as well as on their subsequent intracellular fate. In general, particles can enter cells by various pathways which can be analyzed by different methods, such as confocal laser scanning microscopy (CLSM), fluorescence-activated cell sorting (FACS), or focused ion beam milling/scanning electron microscopy (FIB/SEM), depending on the cell type and the physicochemical properties of the nanoparticle ${ }^{43,45}$. The uptake of unfunctionalized silica particles by NR8383 macrophages as relevant cell type in particle contact ${ }^{23,27}$. After $24 \mathrm{~h}$ of incubation was analyzed in detail using cross-sectional analysis of single cells by FIB/SEM and subsequent TEM/EDX of FIB-prepared cell lamellae. Figure 5 shows representative SEM images after FIB cutting of macrophages incubated with spherical silica nanoparticles, submicroparticles, and microparticles. The particles were found as electron-dense structures inside the cells. Notably, neither size nor shape of the nanoparticles were changed by the uptake, however, the nanospheres were mainly present as larger agglomerates.

The chemical identity of the nanoparticles after uptake was demonstrated by TEM and corresponding EDX spectra of the cells (Fig. 6). EDX spectra showed signals for carbon (C), oxygen (O), and silicon (Si). The elements $\mathrm{C}$ and $\mathrm{O}$ were detected in all organic samples due to the presence of organic cell material as shown earlier for untreated hMSC (no exposure to particles) ${ }^{46}$. However, the silicon signal clearly confirms the presence of silica particles. As it is generally accepted, particles are taken up by mammalian cells by endo- and pinocytosis, depending on the cell type as well as on the particle properties, i.e. size, charge (zeta potential), shape, and functionalization ${ }^{43,47-53}$. Typically, particles are localized as agglomerates in membrane-enclosed vesicles within the cells. For silica nanoparticles of spherical and rod-like shape it has been shown that they were all taken up by macrophages, although the endocytosis pathway was dependent on the particle geometry ${ }^{54}$.

The localization of internalized silica particles inside NR8383 cells after $24 \mathrm{~h}$ of exposure was also assessed by CLSM with fluorescent PEI-FITC-labeled particles and LysoTracker Red DND-99, which allowed the labeling and tracking of acidic organelles like endosomes, lysosomes, and endolysosomes. The overlays of the PEI-FITC and LysoTracker signals revealed that all particle types were mainly associated with endo- and lysosomal structures (Fig. 7). It is well accepted that internalized particles mainly end up in endolysosomal compartments ${ }^{46,52,55-57}$. 

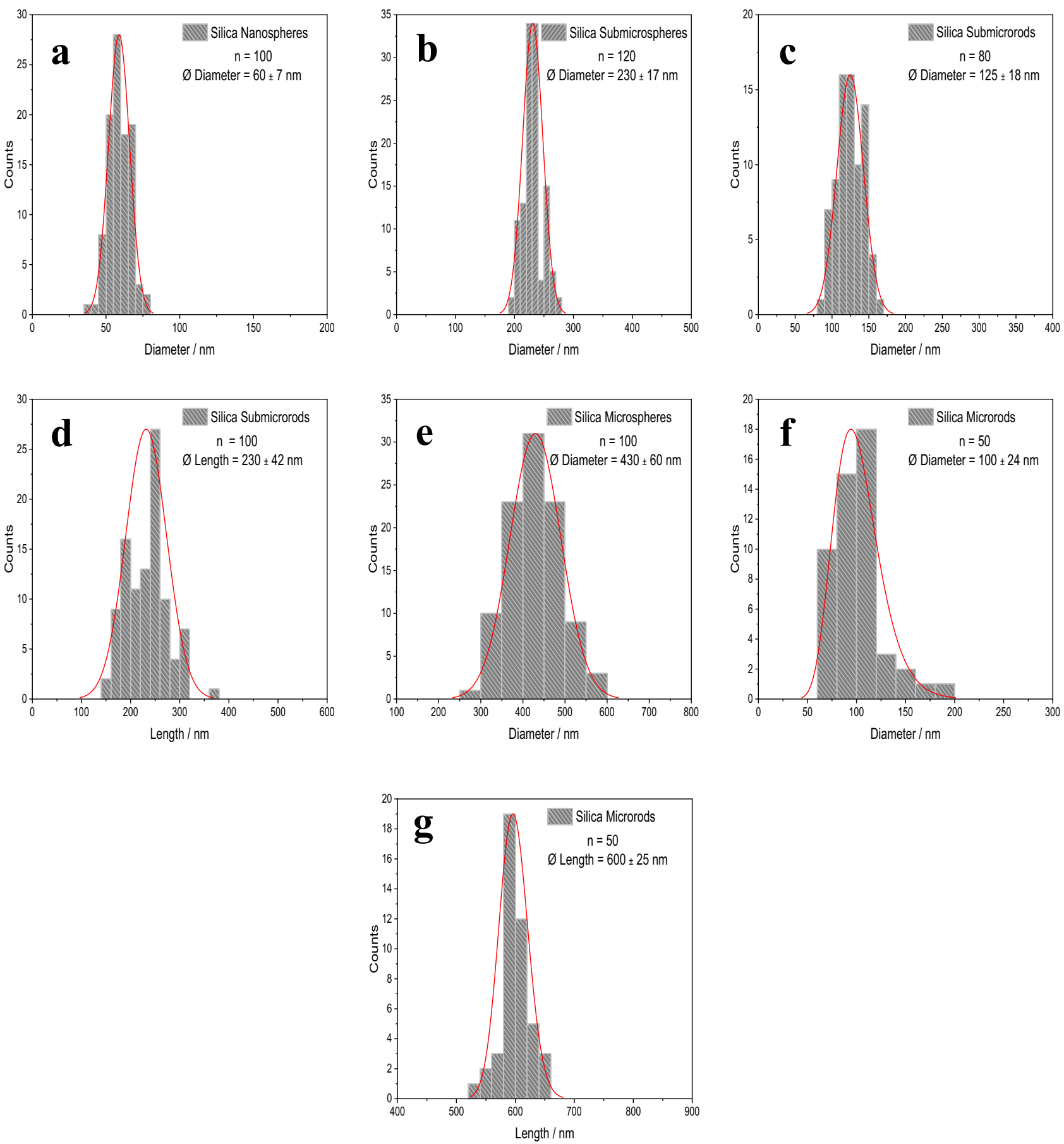

Figure 2. Particle size distribution (LogNormal) by SEM analysis for all unfunctionalized silica particles: Diameter of nanospheres (a), diameter of submicrospheres (b), diameter of submicrorods (c), length of submicrorods (d), diameter of microspheres (e), diameter of microrods (f), length of microrods $(\mathbf{g})$.

The cytotoxic effects of the different silica particles on NR8383 cells at various particle concentrations were determined by propidium iodide (PI) staining of non-viable cells after $16 \mathrm{~h}$ of incubation (Fig. 8). In general, a concentration-dependent uptake of each particle type was observed (correlation coefficient $>0.86$ ) as analyzed by flow cytometry (data not shown). A statistically significant cell toxicity was found for all silica particle morphologies (with nanospheres being the only exception) at high particle concentrations of 200 and $300 \mu \mathrm{gLL}^{-1}$, while concentrations below $200 \mu \mathrm{g} \mathrm{mL}^{-1}$ had no significant effect on the cell viability except the available silica nanoparticles that served as positive control (agglomerated amorphous silica nanoparticles with an agglomerate size of $2000 \pm 1000 \mathrm{~nm})^{36}$. For these, a statistically significant effect on cytotoxicity was observed at $100 \mu \mathrm{g} \mathrm{mL}{ }^{-1}$. Among the spherical silica particles, microspheres exhibited the highest toxicity, which was significantly enhanced compared to nanospheres and submicrospheres, indicating a size-dependent effect. Similarly, in the case of the 

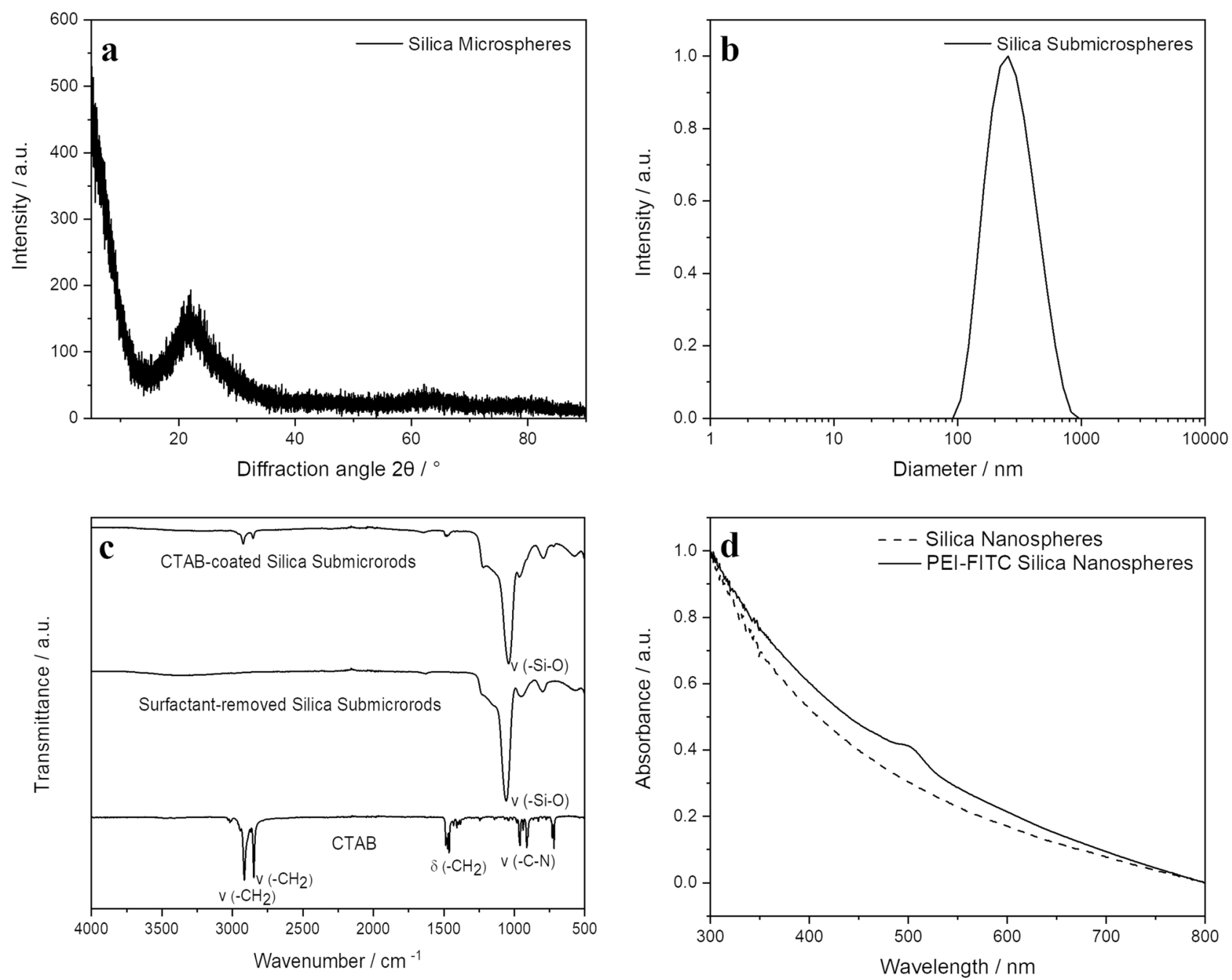

Figure 3. Representative characterization data of unfunctionalized silica particles (a-d) and for fluorescent silica particles (d): XRD shows amorphous particles (a), DLS shows well-dispersed particles (b), IR spectroscopy confirms the removal of CTAB after the synthesis (c), and UV/vis spectroscopy confirms the attachment of PEIFITC (d). The particles with other morphologies had very similar properties.

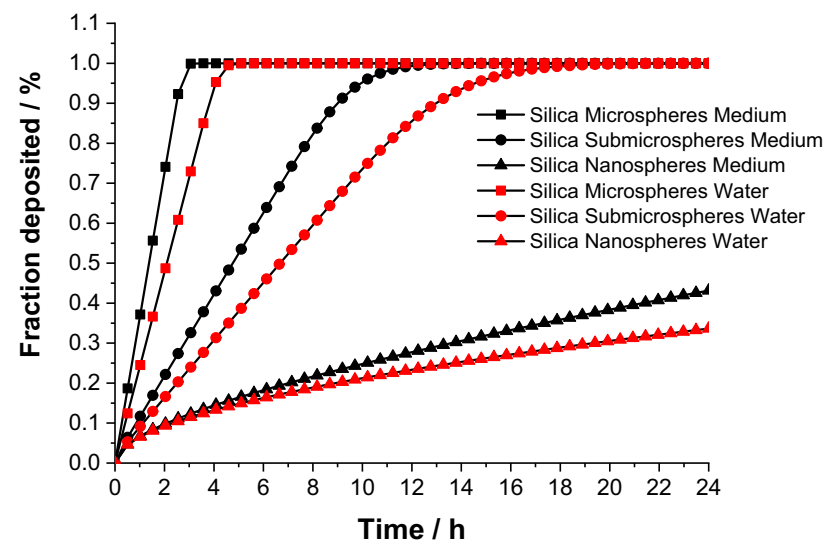

Figure 4. Precipitation and diffusion of spherical silica particles according to the ISDD model in water and in cell culture medium (DMEM supplemented with 10\% FCS). 


\begin{tabular}{|c|c|c|c|c|c|c|c|}
\hline & $\begin{array}{l}\text { Silica }\left(\mathrm{SiO}_{2}\right) \\
\text { concentration/ } \\
\text { mmol L }{ }^{-1}\end{array}$ & $\begin{array}{l}\text { Silica particle } \\
\text { concentration } / \mathrm{L}^{-1}\end{array}$ & $\begin{array}{l}\text { Silica particle } \\
\text { surface } / \mathbf{m}^{2} \text { per } \\
\text { particle }\end{array}$ & $\begin{array}{l}\text { Total silica particle } \\
\text { surface } / \mathrm{m}^{2} \mathrm{~L}^{-1}\end{array}$ & $\begin{array}{l}\text { Total silica particle } \\
\text { surface per well } \\
(640 \mu \mathrm{L}) / \mathrm{m}^{2}\end{array}$ & $\begin{array}{l}\text { Total silica particle } \\
\text { surface per cell } \\
(48,000 \text { cells }) / \mu m^{2}\end{array}$ & $\begin{array}{l}\text { Total silica } \\
\text { concentration } \\
\text { after complete } \\
\text { sedimentation in } \\
\text { the well/particles } \\
\mathrm{m}^{-2}\end{array}$ \\
\hline Nanospheres & 1.7 & $4.42 \times 10^{14}$ & $1.13 \times 10^{-14}$ & 5.0 & $3.2 \times 10^{-3}$ & 67,000 & $1.41 \times 10^{15}$ \\
\hline Submicrospheres & 1.7 & $7.85 \times 10^{12}$ & $1.66 \times 10^{-13}$ & 1.3 & $8.3 \times 10^{-4}$ & 17,000 & $2.51 \times 10^{13}$ \\
\hline Submicrorods & 1.7 & $2.77 \times 10^{13}$ & $8.01 \times 10^{-14}$ & 2.2 & $1.4 \times 10^{-3}$ & 29,000 & $8.86 \times 10^{13}$ \\
\hline Microspheres & 1.7 & $1.20 \times 10^{12}$ & $5.81 \times 10^{-13}$ & 0.70 & $4.5 \times 10^{-4}$ & 9,300 & $3.84 \times 10^{12}$ \\
\hline Microrods & 1.7 & $1.06 \times 10^{13}$ & $1.96 \times 10^{-13}$ & 2.1 & $1.3 \times 10^{-3}$ & 28,000 & $3.40 \times 10^{13}$ \\
\hline
\end{tabular}

Table 2. Dose data for all cell culture studies with silica particles $\left(100 \mu \mathrm{g} \mathrm{mL}^{-1}\right)$ in a 24 -well plate $\left(2 \mathrm{~cm}^{2}, 640\right.$ $\mu \mathrm{L}, 48,000$ cells). As the cytotoxic effects of particles have been related to their total surface area, also with respect to the number of cells, the data were converted to different ratios (see discussion).
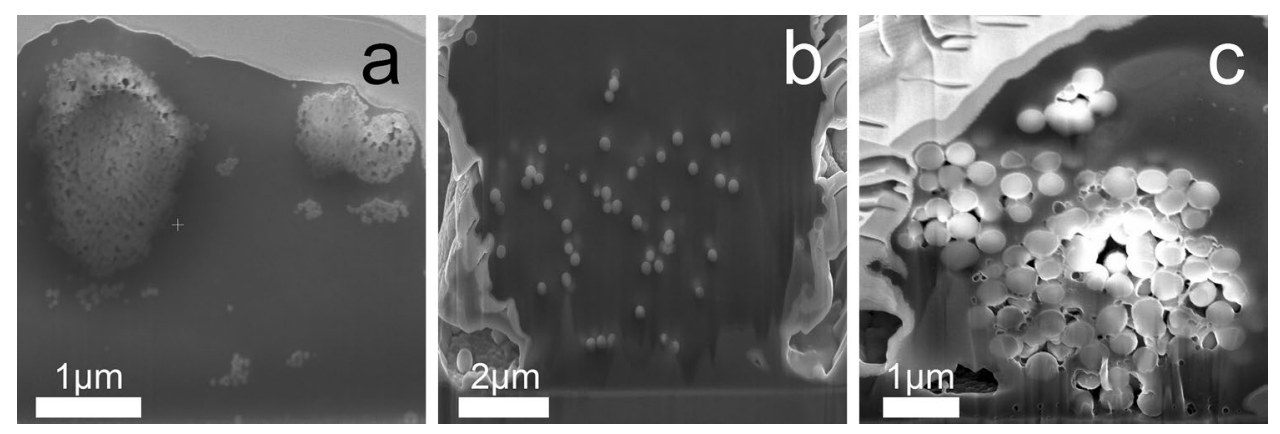

Figure 5. Representative SEM images of unfunctionalized silica particles in dissected (FIB milling) NR8383

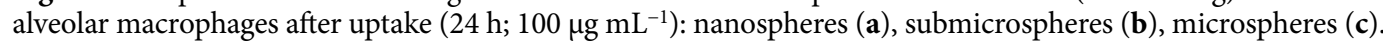

rod-shaped particles the cell toxicity of microrods was significantly higher compared to submicrorods. In general, the cytotoxic concentrations agree with the literature on silica (nano-)particles ${ }^{1,8,18}$.

Reactive oxygen species (ROS) generated by NR8383 macrophages after $2 \mathrm{~h}$ of exposure to silica particles of different morphologies were detected by the dichlorofluorescein (DCF) assay (Fig. 9). Significantly enhanced ROS levels in comparison to untreated cells which can be associated with cell activation were detected for silica nanospheres, submicrospheres and submicrorods, similar to the positive control $\left(3 \% \mathrm{H}_{2} \mathrm{O}_{2}\right.$ served as positive control). Silica microspheres and microrods did not affect ROS production. Cell activation was most pronounced for the submicroparticles (submicrospheres and submicrorods) and significantly enhanced compared to both nano- and microparticles.

The effects of different silica particles on the expression of bioactive factors by NR8383 macrophages were investigated with cell culture supernatants after $16 \mathrm{~h}$ of particle exposure $\left(100 \mu \mathrm{g} \mathrm{mL}^{-1}\right.$; subtoxic level $)$ and a chemiluminescence-based protein microarray which allowed the simultaneous detection of 79 signaling molecules like cytokines, chemokines, and growth factors. Based on the proteomic repertoire of NR8383 cells as reported by Duhamel et al. ${ }^{58}, 27$ of the 79 detected factors were selected for a detailed analysis. The qualitative heat map in Fig. 10 showed the relative expression levels of the selected factors.

The factors IL-1 $\beta$, GDF-15, TNF- $\alpha$, and CXCL1 were selected for a detailed quantitative analysis by SandwichELISA (Fig. 11). All silica particle types significantly enhanced the release of IL-1 $\beta$, compared to an untreated control at a particle concentration of $200 \mu \mathrm{g} \mathrm{mL} \mathrm{m}^{-1}$, indicating an inflammatory response of the NR8383 cells. At this particle concentration, the GDF-15 release was also increased in the presence of microspheres and the rod-shaped submicro- and microparticles, whereas the TNF- $\alpha$ release was increased only by nanospheres and microrods. However, a silica concentration of $200 \mu \mathrm{g} \mathrm{mL}{ }^{-1}$ was already associated with cytotoxicity (Fig. 8). At subtoxic particles concentrations of $100 \mu \mathrm{g} \mathrm{mL}^{-1}$, none of the silica particles induced a significant cell activation, except for the increased GDF-15 release in the presence of microspheres. Furthermore, the expression of the chemokine CXCL1 was not affected by any particle type. In addition, a particle size-dependent effect on the activation of NR8383 was not observed in this study.

The potential of chemotactic factors released from NR8383 cells to recruit leukocytes (dHL-60 cells) was finally analyzed by the PICMA (Fig. 12). There were only small effects of all kinds of silica particles compared to the positive control, and there was no significant difference between the particle types. Remarkably, the commercially acquired silica particles, which served as positive control, had a significantly higher effect than the newly synthesized silica particles. 

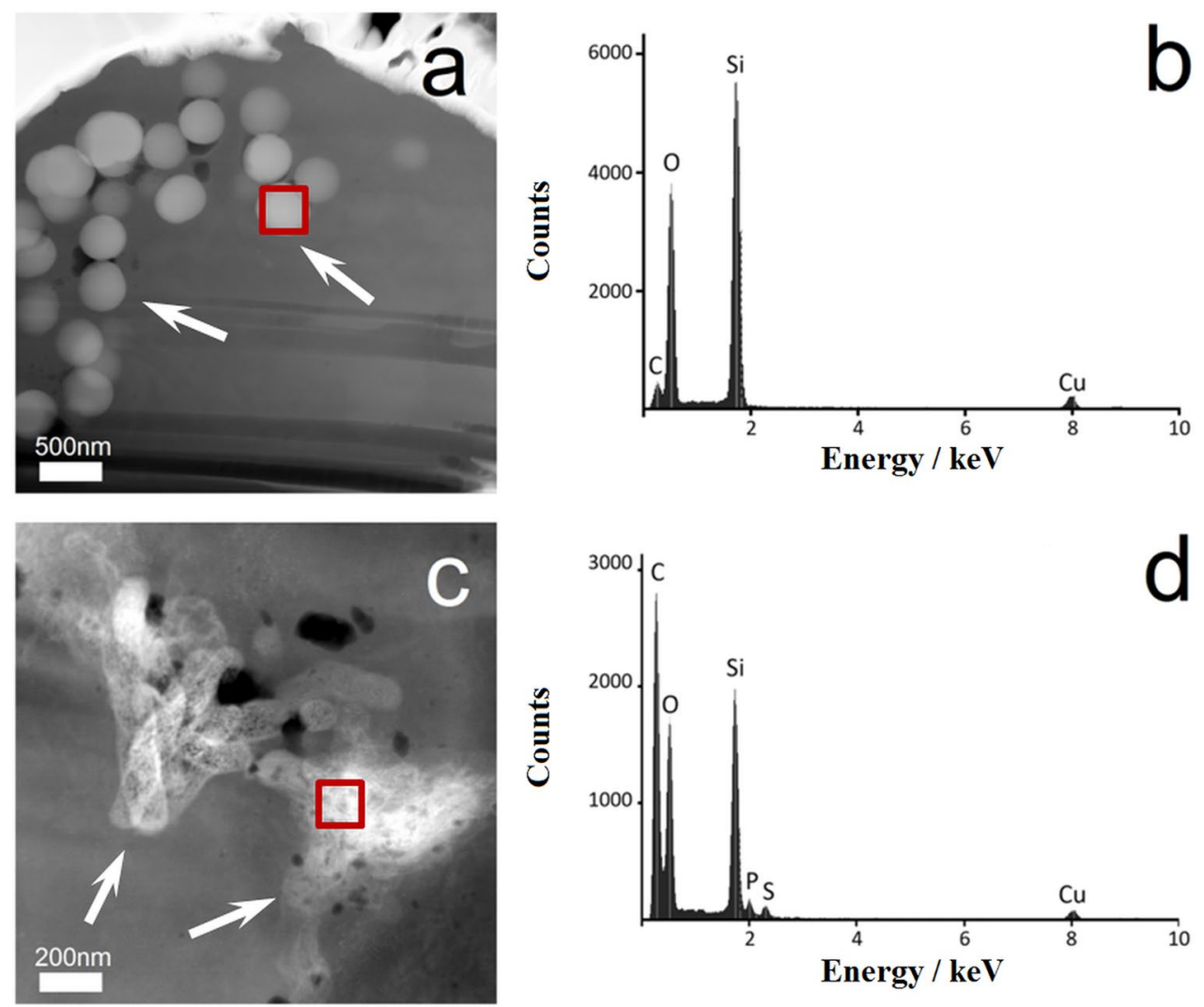

Figure 6. Representative TEM/EDX analyses of FIB-prepared cell lamellae from single NR8383 cells after $24 \mathrm{~h}$ of exposure to $100 \mu \mathrm{g} \mathrm{mL} L^{-1}$ unfunctionalized silica particles. The thickness of each TEM lamella was $100 \mathrm{~nm}$. TEM images of cell lamellae were prepared after incubation with microspheres (a) or microrods (c); white arrows indicate particles inside the cells. Corresponding EDX spectra (b and $\mathbf{d})$ of the elements detected within the regions of interest of the cell lamellae (red boxes in $\mathbf{a}$ and c) confirmed the presence of silica.

\section{Discussion}

Usually, smaller silica nanoparticles have a higher cytotoxicity and a higher potential for the release of proinflammatory cytokines ${ }^{8,27}$. Chen et al. have reviewed the effect on the immune system and their interaction with the corresponding cells, including macrophages ${ }^{27}$. The specific surface area has been proposed as a major parameter for the cytotoxicity effects of silica nanoparticles ${ }^{8,32}$. The same was found for the genotoxicity with macrophages ${ }^{59}$.

We found only small differences between the five kinds of particles. Cytotoxic effects were only observed at high concentrations, i.e. $\geq 200 \mu \mathrm{g} \mathrm{mL} \mathrm{m}^{-1}$, with the microparticles being significantly more toxic $(\mathrm{MS} \approx \mathrm{MR}>\mathrm{SMR} \approx \mathrm{SMS} \approx \mathrm{NS})$ than the nanoparticles. In addition, our data on ROS formation showed that the sedimentation rate of particles (Fig. 4, particle-cell-contact) and the particle dose which is influenced by the size of the particles (the smaller the particles, the higher the dose in cell culture), probably influenced the formation of ROS. This in turn means that at a higher particle dose in cell culture (NS $>$ SMS $>$ MS) and a higher sedimentation rate $(\mathrm{MS}>\mathrm{SMS}>\mathrm{NS}$ ) of silica particles, more ROS will be formed (Table 2). Table 3 gives a qualitative overview on the biological effects of the particles. Despite small differences, no particle type induced significant adverse effects on the cells in the subtoxic concentration range. Apparently, neither the particle size nor the particle shape play a significant role in contact with NR8383 macrophages or dHL-60 leukemia cells. However, differences in assay conditions may explain differences between published studies. It has been reported that the presence of serum within cell culture medium enhanced the polydispersity index and the hydrodynamic diameter of silica nanoparticles and led to decreased toxic effects ${ }^{33}$. However, is also not always clear in published studies whether the analyzed particles were agglomerated or dispersed.

While the biological effects of the newly synthetized silica particles differed only slightly from each other, the strongest particle-induced chemotaxis was caused by the commercially acquired silica nanoparticles, which served as positive control (Fig. 12). The characterization of these particles in a previous work ${ }^{36}$. showed a clear agglomeration with a particle size of $2000 \pm 1000 \mathrm{~nm}$ that leads to a rapid sedimentation onto the cells. In the present study, the silica positive control was the only particle type that was clearly agglomerated. This observation is consistent with the hypothesis that stronger effects of nano-sized compared to micro-sized particles can be explained by the higher volume consumption of their agglomerates in the lysosomes of phagocytizing alveolar macrophages $^{60,61}$. 

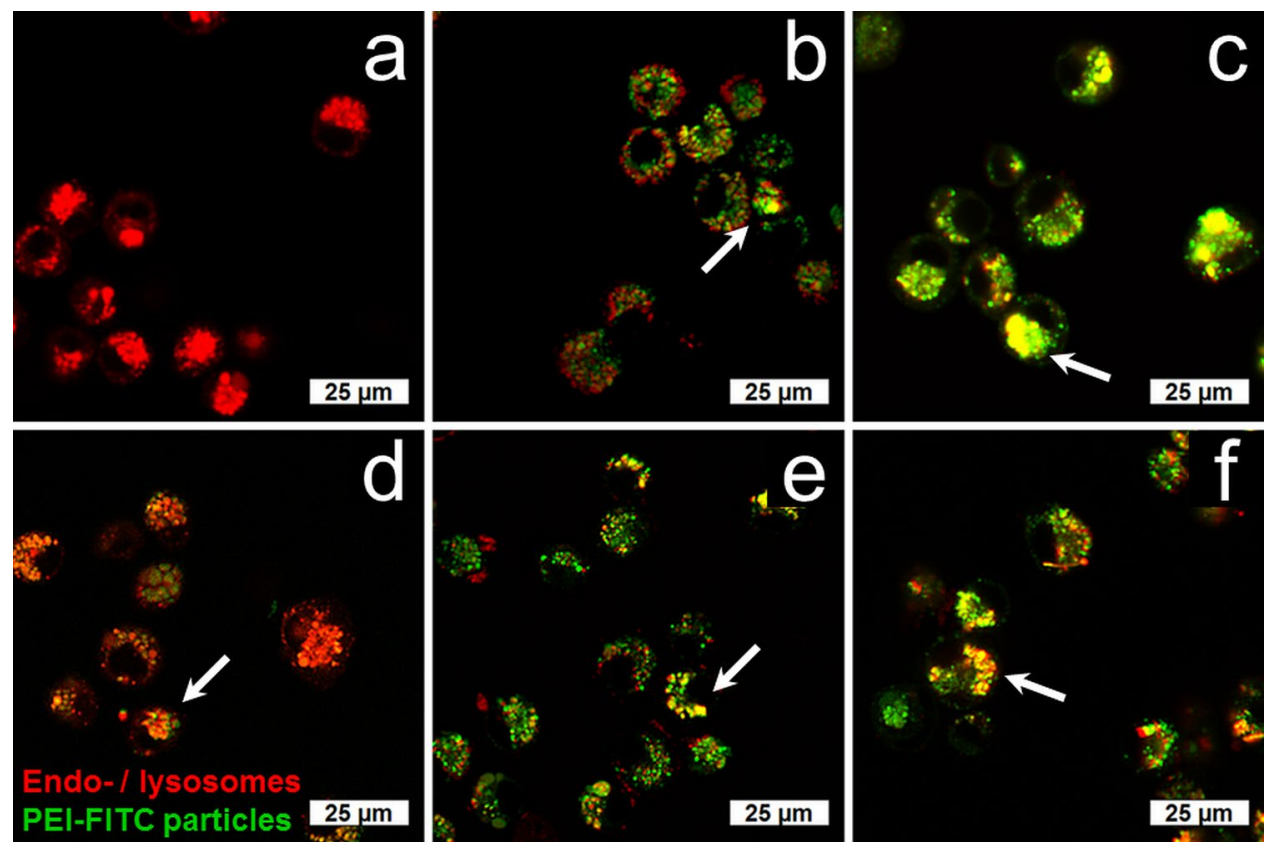

Figure 7. Localization of silica particles in NR8383 alveolar macrophages after incubation with PEI-FITClabeled silica particles $\left(100 \mu \mathrm{g} \mathrm{mL}^{-1}\right)$ for $24 \mathrm{~h}$ by confocal laser scanning microscopy (CLSM). The red fluorescence signals represent endo-/lysosomes stained by LysoTracker Red DND-99. The green signals represent PEI-FITC-labeled silica particles. The overlay of both signals (yellow, indicated by white arrows) indicates a co-localization of particles in endo-/lysosomes. The representative fluorescence micrographs show the results for untreated cells as control (a), and cells treated with nanospheres (b), submicrospheres (c), microspheres (d), submicrorods (e), and microrods (f).

The ISDD model gave the fractions of nano-, submicro-, and microspheres delivered to cells during $24 \mathrm{~h}$ in vitro with a medium height (liquid level) of $2.5 \mathrm{~mm}$ in the cell culture well. While the nanoparticles have a lower contact with the cells, both submicro- and microparticles sediment within hours. Due to the higher viscosity and density, the cell-particle contact was generally slower in medium than in pure water. Such differences in the gravitational settling of particles are a possible explanation why microparticles induced an enhanced toxic effect at high concentrations compared to the nanoparticles, consistent with the agglomerated silica positive control.

Wiemann et al. have reported extensive data on the NR8383 alveolar macrophages as in vitro model to assess the inhalation toxicity of particles ${ }^{32}$. In their studies, the particles had mostly sedimented onto the cells after $16 \mathrm{~h}$, usually due to agglomeration. This was also the case for our particles, especially for the bigger ones (submicro and micro particles). They have classified "naked" silica particles ( 5 to $50 \mathrm{~nm}$ ) as biologically active and ligandcoated silica particles as inactive. Wiemann et al. defined a threshold value of $4000 \mu \mathrm{m}^{2}$ per cell for the distinction between active and passive materials. As shown in Table 2, these values are exceeded at $100 \mu \mathrm{gL}^{-1}$ for all our particles. Thus, we can conclude in line with Wiemann et al. that the observed effects were mostly due to particle overload and not to a particle-specific toxicity, in agreement with earlier opinions ${ }^{1,18}$. A significant cytotoxic effect of particle size or particle shape cannot be deduced from our data; the particles cause only low adverse effects.

\section{Conclusions}

Five different types of chemically identical silica particles without surface functionalization which differ only in size and shape were prepared. All particles were readily taken up by NR8383 alveolar macrophages. Cytotoxic effects were observed at $200 \mu \mathrm{g} \mathrm{mL}^{-1}$ and above, where the toxicity was probably dependent on the particle-cellcontact (MS $>$ SMS $>$ NS) and the formation of ROS probably by the sedimentation in addition to the particle dose, which is dependent on the size of the particles (the smaller the particles the higher the particle dose). In the subtoxic concentration range $\left(100 \mu \mathrm{g} \mathrm{mL}^{-1}\right)$, all particle types induced the expression of different cytokines. A more detailed analysis of four mainly pro-inflammatory cytokines showed mixed results with no clear differences between the particles. The particle-induced cell migration assay (PICMA) confirmed that all five types of silica particles have only low pro-inflammatory potential. We conclude that at least in this size range (between 60 and $600 \mathrm{~nm}$, considering all particle types) neither particle size nor particle shape are significant parameters for cell-biological effects at subtoxic concentrations. In comparison to crystalline quartz, all samples investigated here consisted of amorphous hydrated silica. The lower toxicity in comparison to quartz may be due to the hydrated state of the surface in comparison to the oxidic and more ordered crystalline surface of quartz. Further studies are necessary to elucidate the difference between amorphous and crystallize $\mathrm{SiO}_{2}$ species. 


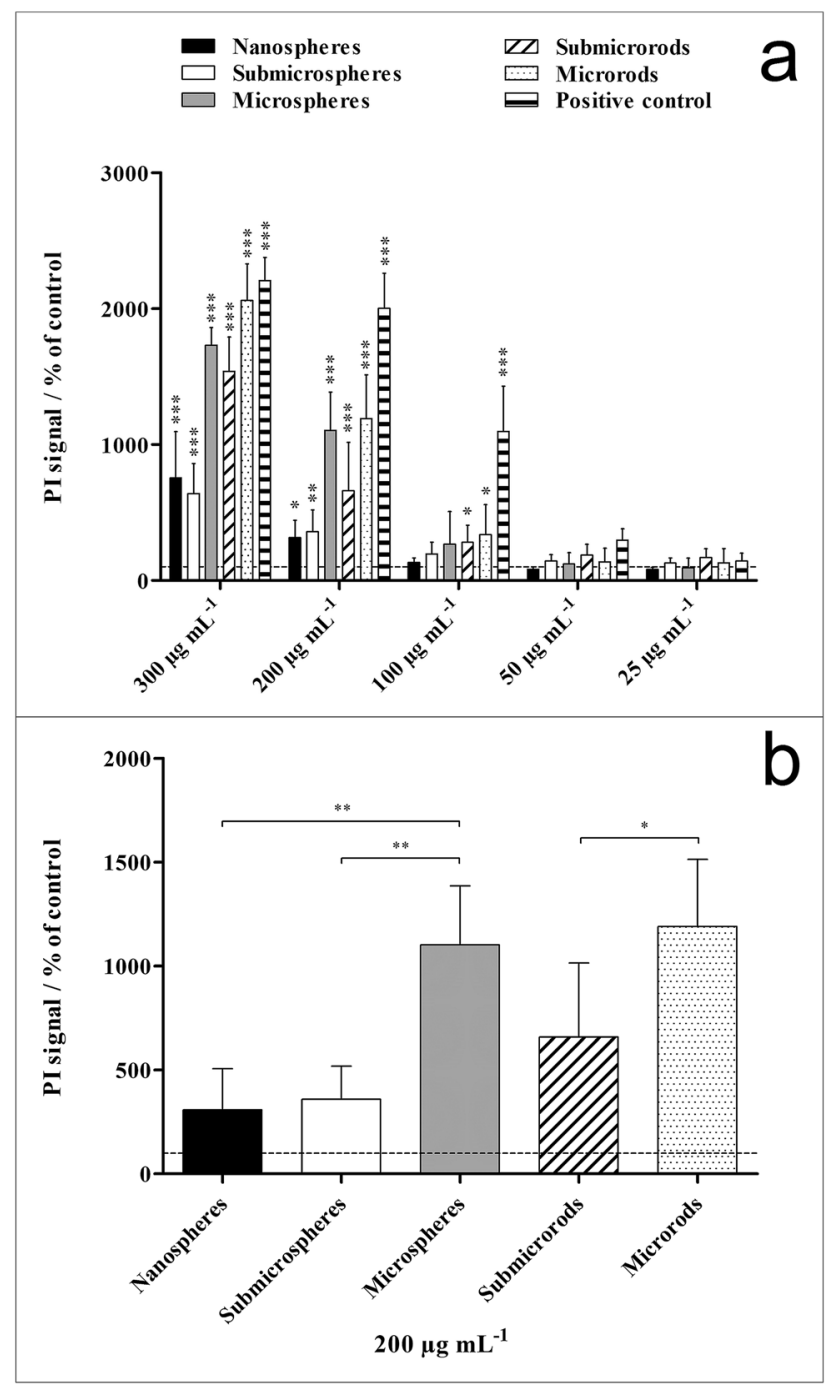

Figure 8. Viability of NR8383 alveolar macrophages after $16 \mathrm{~h}$ incubation with different unfunctionalized silica particles. The cell viability was determined by propidium iodide (PI) staining of non-viable cells and mean PI fluorescence intensity assessment by flow cytometry. Commercial silica particles served as positive control. (a) Comparison of the effects of different particle concentrations and morphologies on the cell viability. (b) Comparison of the effects of different particle morphologies on the cell viability at a particle concentration of $200 \mu \mathrm{g} \mathrm{mL} \mathrm{m}^{-1}$. Data are expressed as mean $\pm \mathrm{SD}(n=3)$, given as percentage of the control (100\%, untreated cells). Asterisks $\left({ }^{*}\right)$ indicate significant differences in comparison to the control $\left({ }^{* *} p<0.01,{ }^{* *} p<0.001\right)$.

\section{Methods}

Chemicals. We used tetraethyl orthosilicate (TEOS, Alfa Aesar, 98\%), aqueous ammonia $\left(\mathrm{NH}_{3}, 25-30 \%\right.$, Carl Roth), ethanol (p.a., Fisher Chemicals), cetyltrimethylammonium bromide (CTAB, Sigma-Aldrich, 99\%), branched polyethyleneimine (PEI, $M_{\mathrm{w}}=25,000 \mathrm{~g} \mathrm{~mol}^{-1}$, Sigma-Aldrich), and fluorescein-labeled polyethyleneimine (PEI-FITC, $M_{\mathrm{w}}=25,000 \mathrm{~g} \mathrm{~mol}^{-1}$, Sigma-Aldrich) as obtained. All syntheses were carried out in ultrapure water (Purelab ultra instrument from ELGA). Prior to the syntheses, the glassware was cleaned first with boiling aqua regia and then twice with boiling water. The particles were isolated by centrifugation with a Heraeus Fresco 21 centrifuge (Thermo Scientific). All particles were endotoxin-free as analyzed by the Limulus Amebocyte Lysate test with a detection limit of $<0.01 \mathrm{EU} \mathrm{mL}^{-1}$ (Endosafe nexgen-PTS, Charles River) ${ }^{62}$.

Instruments. For dynamic light scattering for particle size analysis and zeta potential determination, we used a Malvern Zetasizer Nano ZS ZEN 3600 instrument (Malvern Panalytical Ltd.; $25^{\circ} \mathrm{C}$, laser wavelength $633 \mathrm{~nm}$ ), operating at a fixed angle of $173^{\circ}$ in backward scattering mode. The peak profile of the size distribution was analyzed by a log-normal distribution fit. The average particle diameter is given as mean value of the maximum of the size distribution from the log-normal distribution fit analysis and the empirical standard deviation as given by the instrument software. 


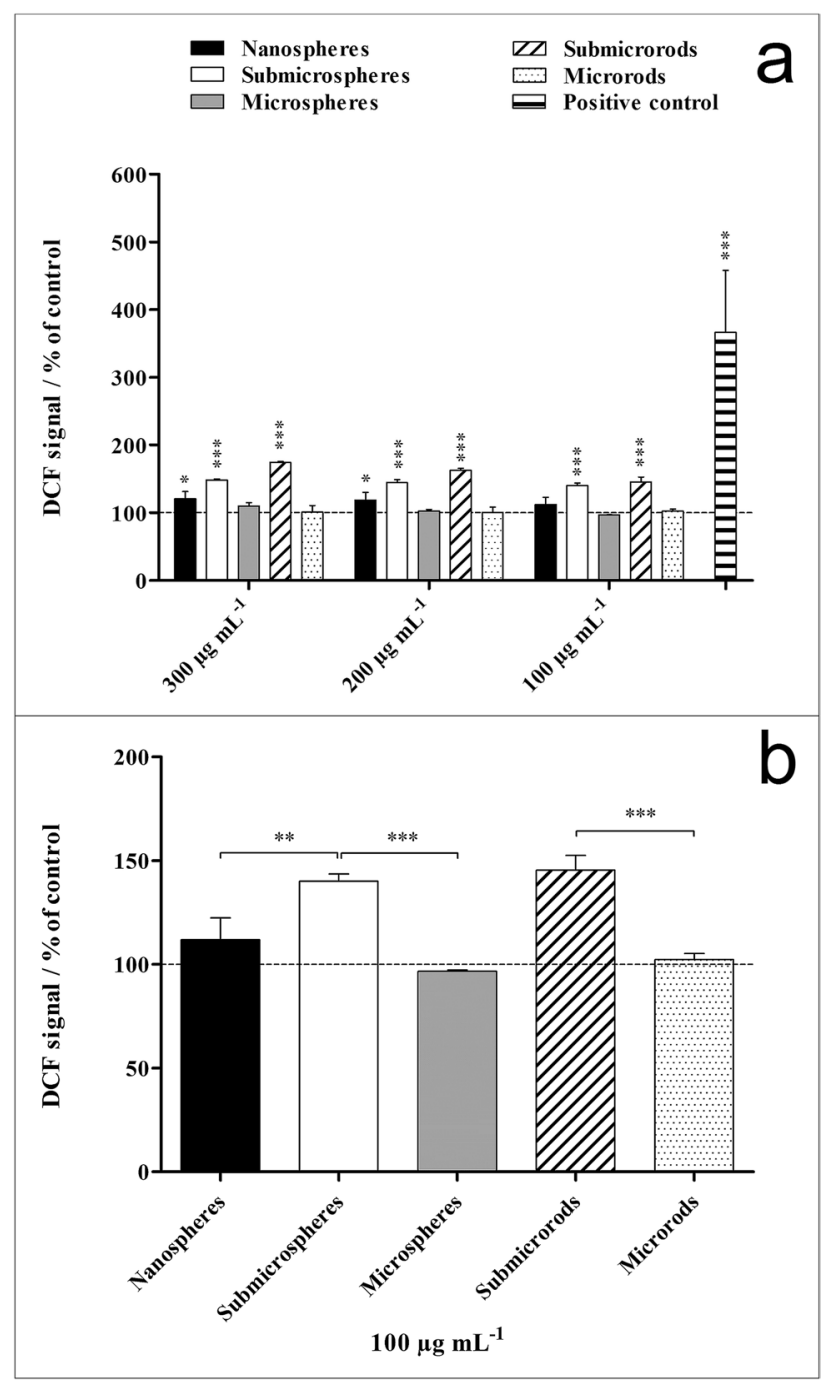

Figure 9. Generation of ROS in NR8383 alveolar macrophages after 2 h exposure to different unfunctionalized silica particles. ROS generation was assessed by the mean fluorescence intensity of dichlorofluorescein (DCF) using flow cytometry. A solution of $3 \% \mathrm{H}_{2} \mathrm{O}_{2}$ served as positive control. (a) Comparison of the effects of different particle concentrations and morphologies on the ROS generation. (b) Comparison of the effects of different particle morphologies on the ROS generation at a particle concentration of $100 \mu \mathrm{g} \mathrm{mL} \mathrm{L}^{-1}$ (subtoxic level). Data are expressed as mean \pm SD $(n=3)$, given as the percentage of the control (100\%, untreated cells). Asterisks $\left(^{*}\right)$ indicate significant differences in comparison to the control $\left({ }^{*} p<0.05,{ }^{* *} p<0.01,{ }^{* * *} p \leq 0.001\right)$.

Ultraviolet-visible spectroscopy (UV/vis) was carried out with a Varian Cary 300 instrument (Agilent Technologies, Inc.) in Suprasil micro quartz cuvettes with a sample volume of $750 \mu \mathrm{L}$ after dilution and background correction.

Fourier-transformed infrared spectroscopy (FT-IR) was performed with an Attenuated Total Reflection (ATR) Bruker Alpha Platinum FT-IR spectrometer. FT-IR spectra of dried silica particles and pure CTAB were obtained by pressing them onto a diamond plate.

Confocal laser scanning microscopy was performed with a Zeiss LSM 700 instrument (Carl Zeiss Microscopy $\mathrm{GmbH}$, Jena, Germany). Fluorescence images were taken (Zeiss LSM 700 microscope and Zen 2010 software) and digitally processed using Adobe Photoshop 7.

Flow cytometric analyses were carried out with an FACSCalibur flow cytometer (BD Bioscience, Heidelberg, Germany). For each measurement, 10,000 cells were analyzed and the data were quantified with the CELLQuest 1.2.2 software (BD Biosciences).

Scanning electron microscopy of the particles was performed with a microscope type FEI ESEM Quanta 400 FEG (ThermoFisher). Prior to the investigation, the samples were sputter-coated with a thin conductive AuPd 80:20 layer.

For X-ray powder diffraction, we isolated the nanoparticle dispersion, shock-froze it with liquid nitrogen, and lyophilized it at $0.31 \mathrm{mbar}$ and $-10^{\circ} \mathrm{C}$ in a Christ Alpha 2-4 LSC freeze-dryer. X-ray powder diffraction was carried out with a Bruker D8 ADVANCE (Bruker Corp.) diffractometer operating in Bragg-Brentano geometry 


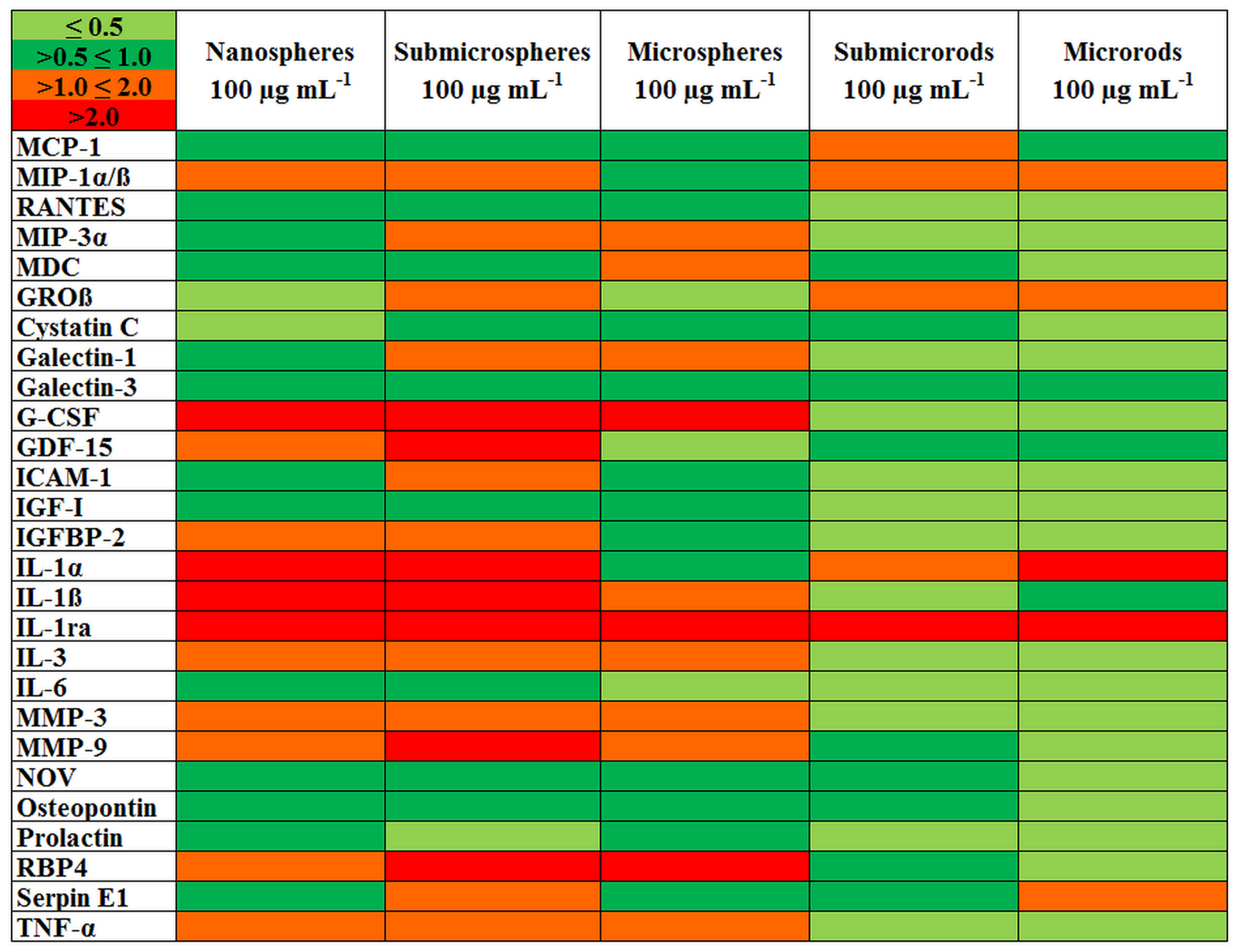

Figure 10. Heat map of 27 bioactive factors of the proteomic repertoire of NR8383 alveolar macrophages after $16 \mathrm{~h}$ of exposure to different unfunctionalized silica particles at $100 \mu \mathrm{g} \mathrm{mL} \mathrm{L}^{-1}$ (subtoxic level) as obtained by protein microarrays. Each row of the heat map represents the expression of one factor relative to its expression in supernatants of NR8383 cells without particle exposure (control). The green colors represent lower, the red colors represent higher expression of factors relative to the control. The color intensity scale shows fold changes at the upper left corner of the figure.

with $\mathrm{Cu}$ Ka radiation $(\lambda=1.54 \AA$, $40 \mathrm{kV}$ and $40 \mathrm{~mA}$ ). As sample holder, a single-crystalline silicon sample holder with a crystallographic (911) plane to minimize background scattering was used.

The FIB system (type FEI Helios G4 CX) consisted of an electron column and an ion column. We used gallium as liquid metal ion source to produce cross-sections of cells at an acceleration voltage of $30 \mathrm{kV}$ together with a stepwise current reduction from 22 to $2.7 \mathrm{nA}$. SEM images were recorded at an acceleration voltage of $5 \mathrm{kV}$. TEM imaging and EDX analysis were performed with a FEI Tecnai F20 instrument.

Synthesis of silica particles. Silica nanospheres, submicrospheres, and microspheres were obtained by a modified Stöber process, following the protocols described in the literature with some modifications ${ }^{39,40}$. For nanospheres, ammonia $(13.2 \mathrm{~mL}, 25 \%)$ was added to ethanol $(200 \mathrm{~mL})$ at $68{ }^{\circ} \mathrm{C}$ under continuous stirring. After $30 \mathrm{~min}$, TEOS $(5.2 \mathrm{~mL})$ was added to the mixture. The reaction was continued with stirring for $4 \mathrm{~h}$ at $68{ }^{\circ} \mathrm{C}$, followed by stirring at room temperature for $12 \mathrm{~h}$. The nanoparticles were isolated by centrifugation and redispersion in water $\left(3,500 \mathrm{rpm}, 90 \mathrm{~min}\right.$, three times), redispersed in ethanol, and dried in air at $200{ }^{\circ} \mathrm{C}$ for $3 \mathrm{~h}$. For submicrospheres, the procedure consisted of mixing water $(6.1 \mathrm{~mL})$ and ammonia $(2.8 \mathrm{~mL}, 30 \%)$ at $47^{\circ} \mathrm{C}$ in ethanol $(50 \mathrm{~mL})$, followed by the addition of TEOS $(6.2 \mathrm{~mL})$ and stirring for $4 \mathrm{~h}$. After $4 \mathrm{~h}$, the reaction mixture was cooled to room temperature and stirred for another $16 \mathrm{~h}$. The particles were isolated and purified as described above. Microspheres were synthesized by the following procedure: Ammonia (4.2 mL, $30 \%)$ and water $(4.8 \mathrm{~mL})$ were added to ethanol $(50 \mathrm{~mL})$ at room temperature under continuous stirring for $20 \mathrm{~min}$. Then, TEOS $(4.9 \mathrm{~mL})$ was added and the mixture was stirred for another $16 \mathrm{~h}$ at room temperature. After synthesis, silica microspheres were collected by centrifugation $(3,500 \mathrm{rpm}, 30 \mathrm{~min})$ and washed with ethanol several times.

Silica submicrorods and microrods were synthesized by a modified Stöber process according to Ref. ${ }^{63}$ with a modified molar ratios of the reagents. For the synthesis of silica submicrorods, CTAB (0.12 g) was dissolved in 


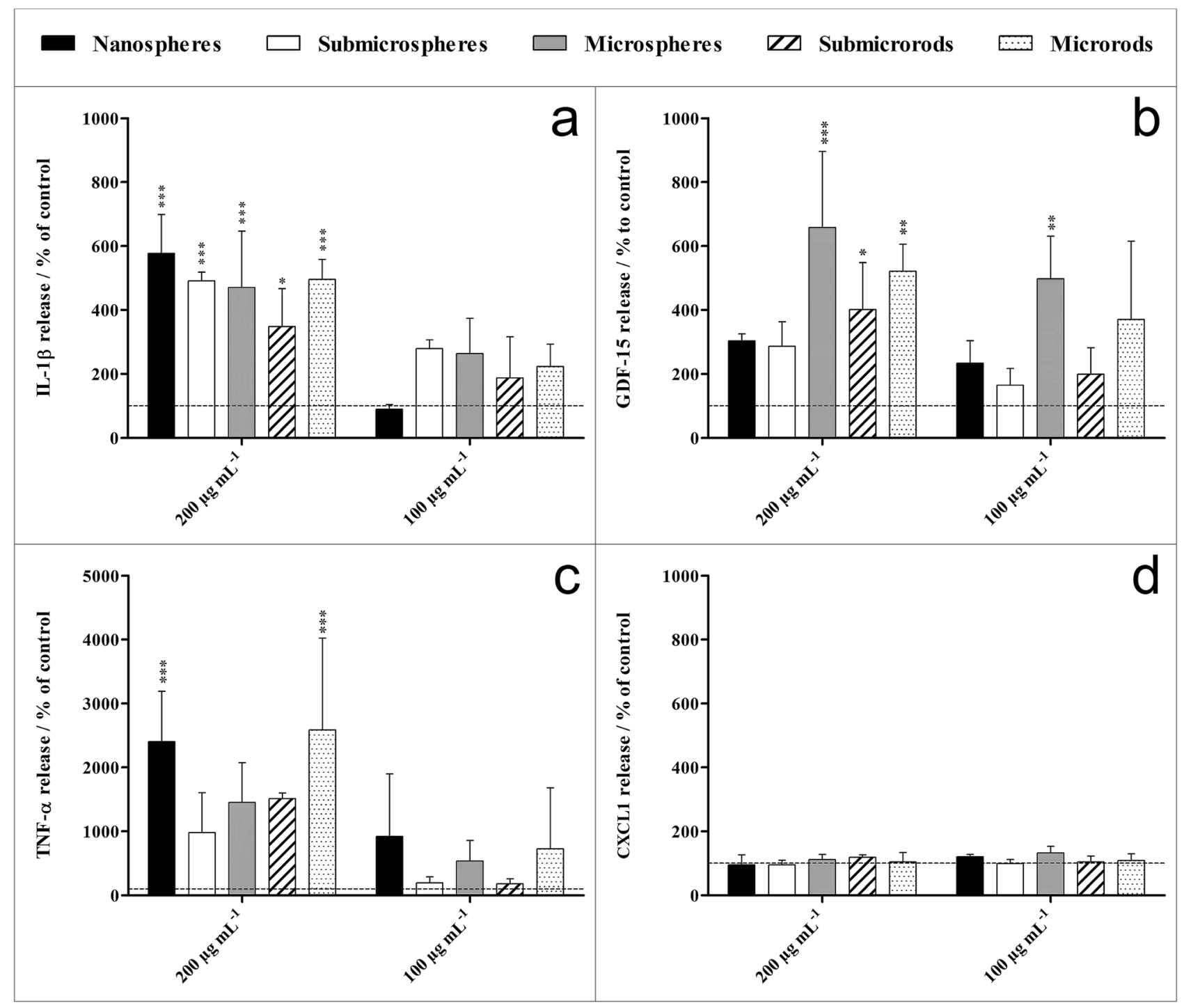

Figure 11. Cytokine release of NR8383 alveolar macrophages after $16 \mathrm{~h}$ exposure to different unfunctionalized silica particles as determined by ELISA. The released amount of IL-1 $\beta$ (a), GDF-15 (b), TNF- $\alpha$ (c), and CXCL1 (d) of untreated cells (not exposed to silica particles) was 30,160, 2 and $14 \mathrm{pg} \mathrm{mL}^{-1}$, respectively. Data are expressed as mean $\pm \mathrm{SD}(n=3)$, given as the percentage of the control (100\%, untreated cells). Asterisks $\left(^{\star}\right)$ indicate significant differences in comparison to the control $\left({ }^{*} p<0.05,{ }^{* *} p<0.01,{ }^{* *} p<0.001\right)$.

water $(30 \mathrm{~mL})$ and stirred at $30^{\circ} \mathrm{C}$ for $30 \mathrm{~min}$. After cooling the solution to room temperature, ammonia $(0.3 \mathrm{~mL}$, $25 \%)$ was added to the CTAB solution and stirred for $20 \mathrm{~min}$. Then, TEOS $(0.25 \mathrm{~mL})$ was added and the reaction mixture was stirred for $1 \mathrm{~h}$. After $7 \mathrm{~min}$, the originally clear solution had assumed a turbid white color. For the synthesis of silica microrods, CTAB $(0.3 \mathrm{~g})$ was completely dissolved in water $(40 \mathrm{~mL})$ and stirred at $30{ }^{\circ} \mathrm{C}$ for $30 \mathrm{~min}$. Ammonia $(1 \mathrm{~mL}, 30 \%)$ was added. After $20 \mathrm{~min}$, TEOS $(1.8 \mathrm{~mL})$ was added and stirring of the reaction mixture was continued at room temperature for $1 \mathrm{~h}$. Silica submicrorods and microrods were collected by centrifugation $(3500 \mathrm{rpm}, 30 \mathrm{~min})$ and washed with ethanol several times. In the next step, the particles were was redispersed in ethanol and heated at $60^{\circ} \mathrm{C}$ for $6 \mathrm{~h}$ in an ethanolic $\mathrm{HCl}$ solution (EtOH: $\left.\mathrm{HCl}=0.99: 0.01 v / v\right)$ to remove the organic surfactant $(\mathrm{CTAB})$. The silica particles were purified by triple centrifugation $(3500 \mathrm{rpm}$, $30 \mathrm{~min}$ ) in ethanol and dried at $200^{\circ} \mathrm{C}$ for $3 \mathrm{~h}$. The quantitative absence of CTAB was shown by IR spectroscopy (Fig. 3).

The number of particles in $1 \mathrm{~g}$ solid was then computed from the average particle mass for spheres and rods:

$$
\begin{gathered}
m_{\text {sphere }}=\frac{4}{3} \pi r^{3} \rho \\
m_{\text {rod }}=\pi r^{2} L \rho
\end{gathered}
$$

with $r$ the particle radius and $L$ the particle length, both obtained by SEM (Table 1), and $\rho$ the density of silica $\left(2000 \mathrm{~kg} \mathrm{~m}^{3}\right)^{63}$. The specific surface area of particles $\left(\mathrm{m}^{2} \mathrm{~g}^{-1}\right)$ was calculated as follows: 

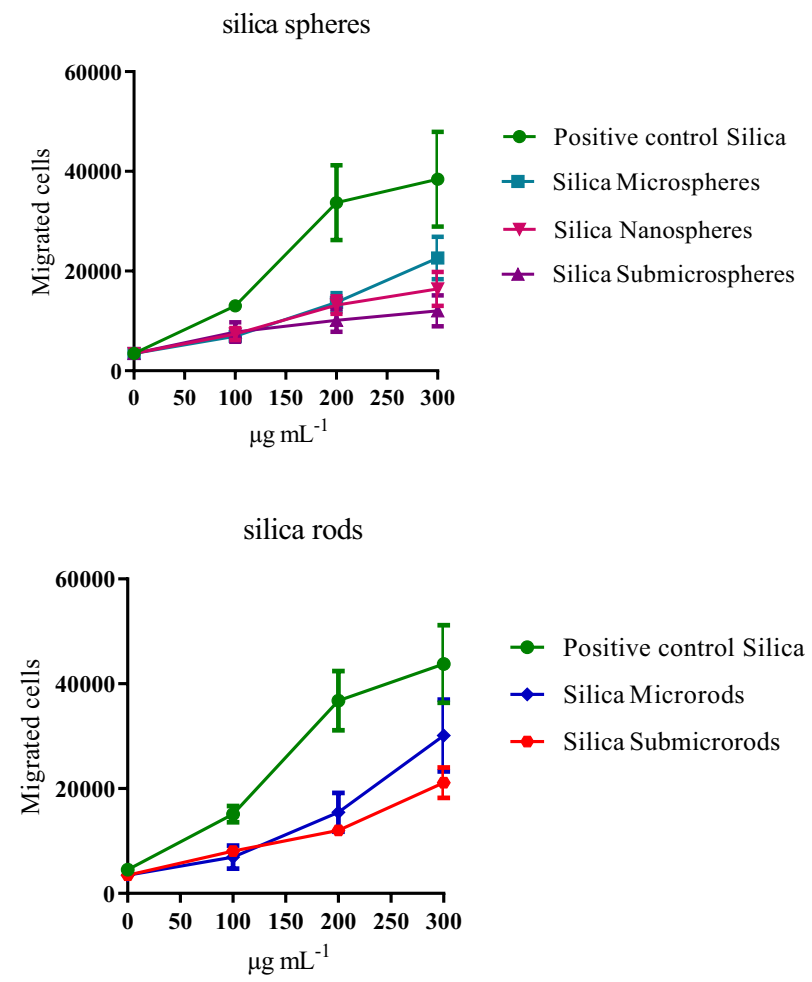

Figure 12. Chemotaxis (migrated cells) of the unexposed dHL-60 cells in response to NR8383 cell supernatants that were obtained from incubations with silica particles between 100 and $300 \mu \mathrm{g} \mathrm{mL} \mathrm{m}^{-1}$. Data are expressed as mean \pm SD $(n=3)$. Commercial silica nanoparticles served as positive control. Top: Spherical silica particles with control. Bottom: Rod-shaped silica particles with control.

\begin{tabular}{|c|c|c|c|c|c|c|c|c|c|}
\hline & Uptake by cells & Relative cytotoxicity & Reactive oxygen species & $\begin{array}{l}\text { Cytokine induction } \\
\text { (overall heat map) }\end{array}$ & IL-1 $\beta$ & GDF-15 & TNF- $\alpha$ & CXCL1 & PICMA \\
\hline Nanospheres & Yes & Low & Low & High & Low & Low & High & Low & Low \\
\hline Submicrospheres & Yes & Low & Intermediate & High & High & Low & Low & Low & Low \\
\hline Submicrorods & Yes & Intermediate & Intermediate & Low & High & High & Low & Low & Low \\
\hline Microspheres & Yes & High & Low & Intermediate & High & High & Low & Low & Low \\
\hline Microrods & Yes & High & Low & Low & High & High & High & Low & Low \\
\hline $\begin{array}{l}\text { Silica positive control } \\
\text { (agglomerated) }\end{array}$ & - & High & - & - & - & - & - & - & High \\
\hline
\end{tabular}

Table 3. Summarized effects of silica particles on NR8383 alveolar macrophages. All data are relative within the five particle types and the positive control.

$$
\begin{gathered}
S_{\text {spheres }}=4 \pi r^{2} N_{\text {particles per 1 g }} \\
S_{\text {rods }}=2 \pi r^{2}+2 \pi r L N_{\text {particles per 1 }} .
\end{gathered}
$$

Functionalization of silica particles with FITC-labeled polyethyleneimine (PEI-FITC). The dried silica particles were surface-functionalized with FITC-labeled polyethyleneimine $\left(4 \mu \mathrm{L}, 1 \mathrm{~g} \mathrm{~L}^{-1}\right)$ by stirring a particle dispersion in ethanol $\left(2 \mathrm{~g} \mathrm{~L}^{-1}\right)$ overnight at room temperature under light exclusion. Purification of the particles was performed by double centrifugation (AMICON Ultra-15 centrifugal filters, MWCO $3 \mathrm{kDa}$, $3,500 \mathrm{rpm}, 45 \mathrm{~min}$ ) in ultrapure water, followed by freeze-drying of the particles. The fluorescently labeled silica particles were freeze-dried with an alpha 2-4 LSC instrument (Christ).

Particle storage and treatment. The unfunctionalized particles were stored after synthesis at $4{ }^{\circ} \mathrm{C}$ in the dark under argon atmosphere. The PEI-labeled particles were freeze-dried after synthesis. Stock dispersions were prepared in water at a particle concentration of $1 \mathrm{~g} \mathrm{~L}^{-1}$. Before adding to the cell culture media, the stock 
dispersions were diluted to 5 to $80 \mathrm{mg} \mathrm{L}^{-1}$. Each dispersion was thoroughly vortexed after dilution and treated in an ultrasonic bath (Elma Sonic S10, $30 \mathrm{~W}, 50 / 60 \mathrm{~Hz}, 450 \mathrm{~mL}$ volume) for $5 \mathrm{~min}$ to obtain well-dispersed particles. All particle preparations were vortexed again immediately before application.

Cell culture. The biological characterization of the particles was performed with the cell line NR8383 (rat alveolar macrophages, LGC Standards GmbH, Wesel, Germany). The cells were cultivated with Ham's F-12 medium containing 15\% fetal calf serum (FCS, GIBCO, Invitrogen, Karlsruhe, Germany) in $175 \mathrm{~cm}^{2}$ cell culture flasks (BD Falcon, Becton Dickinson GmbH, Heidelberg, Germany) at standard cell culture conditions (humidified atmosphere, $37^{\circ} \mathrm{C}, 5 \% \mathrm{CO}_{2}$ ). NR8383 cells were partly adherent and partly non-adherent. The ratio between adherent and non-adherent cells was about 1:1. For cell experiments, adherent cells were detached from the cell culture flasks with a TPP cell scraper (TPP Techno Plastic Products AG, Trasadingen, Switzerland), subsequently combined with non-adherent cells and seeded into 24 -well cell culture plates (BD Falcon) at a concentration of $2.4 \times 10^{5}$ cells $\mathrm{cm}^{-2}$.

Particle uptake analyzed by FIB/SEM, TEM/EDX, and CLSM. We studied the uptake of silica particles by NR8383 cells by cross-sectional analysis of single cells, accomplished by focused ion beam milling (FIB) in combination with scanning electron microscopy (SEM), transmission electron microscopy (TEM), and energy-dispersive X-ray spectroscopy (EDX). After the fabrication of thin lamellae by FIB, the samples were imaged by TEM in combination with EDX for a detailed analysis.

To analyze the uptake of nanoparticles, NR8383 were exposed to $100 \mu \mathrm{g} \mathrm{mL} \mathrm{L}^{-1}$ of unfunctionalized silica particles for $24 \mathrm{~h}$ under cell culture conditions, detached from the culture plate as described above, and seeded on a titanium carrier plate $\left(25 \mathrm{~mm}^{2}\right)$. The cells were washed with PBS (GIBCO, Invitrogen) after $3 \mathrm{~h}$ of adherence under cell culture conditions and fixed with 3.7\% glutaraldehyde (Sigma-Aldrich, Taufkirchen, Germany) in PBS $(v / v)$. The cells were then washed again with PBS and dehydrated in an ascending ethanol row $(50 \%, 70 \%$, $90 \%$, and $100 \%, 5 \mathrm{~min}$ each) according to standard procedures. After the dehydration step, the cell samples were mounted on SEM carriers and finally sputter-coated with $15 \mathrm{~nm}$ gold-palladium layer (K500X, Quorum Technologies Ltd., Ashford Kent, United Kingdom). Before the FIB milling, the samples were furthermore sputter-coated with a thin layer of carbon to protect the cells them from ion contamination and damage during the FIB procedure. The carbon layer was deposited with a gas injection system, delivering gaseous naphthalene that adsorbed to the sample surface. The naphthalene molecules were then decomposed by the electron or ion beam in a defined rectangular position. There, the beam was scanned over the sample surface. The deposited carbon layer remained on the surface, and gaseous decomposition products were removed by a vacuum pump.

Confocal laser scanning microscopy (CLSM) was used for detailed co-localization studies. The NR8383 cells were incubated with $100 \mu \mathrm{g} \mathrm{mL} \mathrm{g}^{-1}$ of PEI-FITC-labeled silica particles for $24 \mathrm{~h}$ under standard cell culture conditions and then stained with $50 \mathrm{nM}$ of a specific endo/lysosomal fluorescent probe (LysoTracker Red DND-99, Invitrogen) in pure Ham's F-12 medium for $30 \mathrm{~min}$ at $37^{\circ} \mathrm{C}$. The cells were analyzed by CLSM after three rinses with Ham's F-12 medium.

Cytotoxicity assay. The cytotoxicity of silica particles was measured and quantified by flow cytometry. As positive control, silica nanoparticles were used (CAS No. 7631-86-9, Lot MKBF2889V, 99.5\%, 10-20 nm) (Sigma-Aldrich, Steinheim, Germany). The particles were previously characterized in detail and consisted of agglomerated X-ray amorphous silica particles with a primary particle size of about $49 \mathrm{~nm}$ and an agglomerate size of about $2 \mu \mathrm{m}^{36}$.

After $16 \mathrm{~h}$ of exposure to various silica concentrations $\left(300,200,100,50,25 \mu \mathrm{g} \mathrm{mL} \mathrm{m}^{-1}\right)$, adherent cells were detached from the cell culture plates with a TPP cell scraper, combined with non-adherent cells and transferred to $5 \mathrm{~mL}$ tubes (BD Biosciences). Non-viable cells were labeled with $50 \mu \mathrm{g} \mathrm{mL} \mathrm{m}^{-1}$ propidium iodide (PI, SigmaAldrich) for $10 \mathrm{~min}$ at room temperature, and the number of non-viable cells (PI positive) was analyzed by flow cytometry.

Generation of reactive oxygen species (ROS). For the analysis of ROS formation induced by the exposure of NR8383 cells to silica particles, a DCF assay was performed by flow cytometry. The cells were incubated with different concentrations of silica particles $\left(300,200,100 \mu \mathrm{g} \mathrm{mL}^{-1}\right)$ for $2 \mathrm{~h}$ under cell culture conditions. A solution of $3 \%$ hydrogen peroxide $\left(\mathrm{H}_{2} \mathrm{O}_{2}\right.$, Herbeta Arzneimittel, Berlin, Germany) served as positive control. The cells were incubated with $3 \% \mathrm{H}_{2} \mathrm{O}_{2}$ for 30 min under cell culture conditions.

Subsequently, $20 \mu \mathrm{M}$ of the cell-permeable ROS indicator 2',7'-dichlorodihydrofluorescein diacetate $\left(\mathrm{H}_{2} \mathrm{DCFDA}\right.$, Thermo Fisher Scientific, Waltham, USA) was added, and the cells were incubated at $37^{\circ} \mathrm{C}$ for $30 \mathrm{~min}$. The non-fluorescent $\mathrm{H}_{2}$ DCFDA diffuses into cells, where it is deacetylated by intracellular esterases and converted to the highly fluorescent $2^{\prime}, 7^{\prime}$-dichlorofluorescein (DCF) form by oxidation. For discrimination between viable and non-viable cells, an additional PI staining was performed.

Protein microarray and ELISA. After incubation of NR8383 cells with different silica particles $\left(100 \mu \mathrm{g} \mathrm{mL} \mathrm{m}^{-1}\right)$ for $16 \mathrm{~h}$, the supernatants were centrifuged at $300 \mathrm{~g}$ for $10 \mathrm{~min}$ and stored at $-20{ }^{\circ} \mathrm{C}$ until the microarray analysis (Profiler Array Rat XL Cytokine Array Kit, Bio-Techne GmbH, Wiesbaden-Nordenstadt, Germany). The assay detected 79 different cytokines, growth factors and other mediators and enabled a semiquantitative analysis. The membrane-based sandwich immunoarray consists of a nitrocellulose membrane on which the captured antibodies are spotted as duplicated dots. Target proteins present in the sample bind to the capture antibodies and are detected with biotinylated detection antibodies and then visualized with chemiluminescent detection reagents. For analysis, the manufacturer's instructions were observed and chemilumines- 
cence signals were detected and quantified by a microarray imager and the ImageQuantTL software (Amersham Imager 600 RGB, GE Healthcare Bio-Science, Uppsala, Sweden). For subsequent detailed analysis using Sandwich-ELISA Kits (R\&D Systems Quantikine, Bio-Techne GmbH, Wiesbaden, Germany), 27 factors were selected based on the proteomic repertoire of NR8383 cells, as reported by Duhamel et al. ${ }^{58}$.

Particle induced cell migration assay (PICMA). NR8383 cells were cultivated at $37^{\circ} \mathrm{C}, 100 \%$ humidity, and $5 \% \mathrm{CO}_{2}$ in Ham's F-12+15\% FCS (fetal calf serum, Biochrom KG, Berlin, Germany), 2 mM L-glutamine, $100 \mu \mathrm{g} \mathrm{mL}-1$ penicillin, and $100 \mathrm{U} \mathrm{mL}^{-1}$ streptomycin. Approximately $3 \times 10^{6}$ cells were seeded in $25 \mathrm{~mL}(175$ $\mathrm{cm}^{2}$ ) medium.

HL-60 cells were obtained from DSMZ (Braunschweig, Germany). For the investigation of chemotaxis, we used trans-retinal differentiated HL-60 cells (dHL-60). The HL-60 cells were cultivated in RPMI 1640 medium (Biochrom KG) $+10 \%$ FSC, $2 \mathrm{mM}$ L-glutamine, $100 \mu \mathrm{g} \mathrm{mL} \mathrm{L}^{-1}$ penicillin, $100 \mathrm{U} \mathrm{mL}^{-1}$ streptomycin, and $1 \mu \mathrm{M}$ trans-retinoic acid at $37^{\circ} \mathrm{C}, 100 \%$ humidity and $5 \% \mathrm{CO}_{2}$ for three days ${ }^{64}$. In general, the dHL-60 cells grow adherent to standard culture dishes.

For the PICMA, NR8383 rat macrophages $\left(3 \cdot 10^{6}\right.$ cells $\left.\mathrm{mL}^{-1}\right)$ were suspended with a vortex in $1 \mathrm{~mL}$ Ham's F-12 medium $+15 \%$ FCS, $2 \mathrm{mM}$ L-glutamine, $100 \mu \mathrm{g} \mathrm{mL}^{-1}$ penicillin, and $100 \mathrm{U} \mathrm{mL}^{-1}$ streptomycin and seeded in $12.5 \mathrm{~cm}^{2}$ cell culture flasks at a final volume of $3 \mathrm{~mL}\left(2.4 \cdot 10^{5} \mathrm{cell}_{\mathrm{sm}}^{-2}\right)$. The assay can also be performed in a smaller volume at constant surface volume ratio.

A sample in which cells without particles were incubated served as negative control. The subsequent experiments were repeated up to concentrations which gave the maximum induction of chemotaxis. Incubation of the NR8383 cells with the particles was performed at $37^{\circ} \mathrm{C}, 100 \%$ humidity, and $5 \% \mathrm{CO}_{2}$ for $16 \mathrm{~h}$. Thereafter, the cells were removed by centrifugation with $300 \mathrm{~g}$ for $5 \mathrm{~min}$ and the particles were removed by centrifugation with $15,000 \mathrm{~g}$ for $10 \mathrm{~min}$ at room temperature. The supernatants were immediately used for the migration tests.

Cell migration was investigated according to Boyden ${ }^{65}$. with the modifications described by Westphal et al. ${ }^{36}$ and Schremmer et al. ${ }^{35}$, applying exclusively permanent cell lines: 200,000 unchallenged dHL-60 cells were added to $200 \mu \mathrm{L}$ RPMI 1640 medium without FCS and seeded in each plate. A well insert (THINCERT, $3 \mu \mathrm{m}$ pore size, Greiner bio-one, Frickenhausen, Germany) was placed into the cavities of 24 black well plates (Krystal, Dunn Labortechnik, Asbach, Germany). $500 \mu \mathrm{L}$ of the supernatants of the particle-incubated NR8383 cells were added to the lower chamber. Migration of dHL- 60 cells across the membrane was performed at $37^{\circ} \mathrm{C}, 100 \%$ humidity, and $5 \% \mathrm{CO}_{2}$ for $24 \mathrm{~h}$. For calibration, 0 to 100,000 HL-60 cells were seeded directly into four-plate wells that were left without inserts.

Staining of migrated cells and of the calibration cells was performed with Calcein-AM for $60 \mathrm{~min}$ at $37^{\circ} \mathrm{C}$, $5 \% \mathrm{CO}_{2}$, and $100 \%$ humidity by adding $500 \mu \mathrm{L}$ Calcein-AM in the plate wells (>90\% HPLC, Sigma-Aldrich, Steinheim, Germany). Calcein-AM was delivered as $4 \mathrm{mM}$ solution in DMSO, stored in aliquots at $-18^{\circ} \mathrm{C}$, and diluted to a final concentration of $4 \mu \mathrm{M}$ in PBS.

The cell suspensions were removed from the plate wells and collected by centrifugation with $300 \mathrm{~g}$ for $5 \mathrm{~min}$ at room temperature. $850 \mu \mathrm{L}$ of the supernatant were discarded while the cells were resuspended in the remaining volume of $150 \mu \mathrm{L}$. In addition, the adherent cells at the outside of the inserts were detached by adding 500 $\mu \mathrm{L}$ trypsin/EDTA $\left(0.05 \% / 0.02 \%\right.$, Biochrom) for $10 \mathrm{~min}$ at $37^{\circ} \mathrm{C}, 5 \% \mathrm{CO}_{2}$, and $100 \%$ humidity. Subsequently, the inserts were removed from the plate wells. Then, $150 \mu \mathrm{L}$ of the collected cells were added into the plate wells that contained the $500 \mu \mathrm{L}$ of the trypsin/EDTA-detached cells. The cell count was determined by fluorescence spectroscopy at 490/520 nm and calculated from the cell calibration (SpectraMax M3, Molecular Devices, Sunnyvale, USA).

Acceptance criteria for a valid test were positive (nanosized silica) and negative controls within the range of the established controls in our laboratory. A positive response was defined as a dose-dependent increase of cell migration of at least two consecutive concentrations with a maximum exceeding the base rate by at least two times at the highest concentration ${ }^{36}$.

The $\mathrm{EC}_{50}$ was calculated separately for each compound using nonlinear regression and the GraphPad Prism 8 software.

As reference, we used a silica reference sample (CAS No. 7631-86-9, Lot MKBF2889V, 99.5\%, 10-20 nm) (Sigma-Aldrich, Steinheim, Germany). The particles were previously characterized in detail and consisted of agglomerated X-ray amorphous silica particles with a primary particle size of about $49 \mathrm{~nm}$ and an agglomerate size of about $2 \mu \mathrm{m}^{36}$.

Statistical analysis. Data are expressed as the mean $\pm \operatorname{SD}(n=3)$ and given as the percentage of the control (cells not exposed to particles). For statistical evaluation, one-way analysis of variance (ANOVA) with Dunett's Multiple Comparison Test was applied using the GraphPad Prism software (GraphPad Software, Inc., CA, USA), while $p$ values $\leq 0.05$ were considered as statistically significant.

Received: 24 September 2020; Accepted: 25 November 2020

Published online: 09 December 2020

\section{References}

1. Fruijtier-Polloth, C. The toxicological mode of action and the safety of synthetic amorphous silica-a nanostructured material. Toxicology 294, 61-79 (2012).

2. Barbé, C. et al. Silica particles: a novel drug-delivery system. Adv. Mater. 16, 1959-1966 (2004).

3. Li, L. et al. In vivo delivery of silica nanorattle encapsulated docetaxel for liver cancer therapy with low toxicity and high efficacy. ACS Nano 4, 6874-6882 (2010). 
4. Vivero-Escoto, J. L., Slowing, I. I., Trewyn, B. G. \& Lin, V. S. Mesoporous silica nanoparticles for intracellular controlled drug delivery. Small 6, 1952-1967 (2010).

5. Singh, P., Srivastava, S. \& Singh, S. K. Nanosilica: Recent progress in synthesis, functionalization, biocompatibility, and biomedical applications. ACS Biomater. Sci. Eng. 5, 4882-4898 (2019).

6. Mohajerani, A. et al. Nanoparticles in construction materials and other applications, and implications of nanoparticle use. Materials 12, 3052 (2019).

7. Aula, S. et al. Biophysical, biopharmaceutical and toxicological significance of biomedical nanoparticles. RSC Adv. 5, 47830-47859 (2015).

8. Jaganathan, H. \& Godin, B. Biocompatibility assessment of Si-based nano- and micro-particles. Adv. Drug Deliv. Rev. 64, 1800-1819 (2012).

9. Tang, L. \& Cheng, J. J. Nonporous silica nanoparticles for nanomedicine application. Nano Today 8, 290-312 (2013).

10. Jain, P. et al. In-vitro in-vivo correlation (IVIVC) in nanomedicine: Is protein corona the missing link?. Biotechnol. Adv. 35, 889-904 (2017).

11. David, C. A. W., Owen, A. \& Liptrott, N. J. Determining the relationship between nanoparticle characteristics and immunotoxicity: key challenges and approaches. Nanomedicine 11, 1447-1464 (2016).

12. Shin, S. W., Song, I. H. \& Um, S. H. Role of physicochemical properties in nanoparticle toxicity. Nanomaterials 5, 1351-1365 (2015).

13. Bruinink, A., Wang, J. \& Wick, P. Effect of particle agglomeration in nanotoxicology. Arch. Toxicol. 89, 659-675 (2015).

14. Cheng, L. C., Jiang, X. M., Wang, J., Chen, C. Y. \& Liu, R. S. Nano-bio effects: interaction of nanomaterials with cells. Nanoscale 5, 3547-3569 (2013).

15. Kelly, P. M. et al. Mapping protein binding sites on the biomolecular corona of nanoparticles. Nat. Nanotechnol. 10, 472-479 (2015).

16. Monopoli, M. P. et al. Physical-chemical aspects of protein corona: relevance to in vitro and in vivo biological impacts of nanoparticles. J. Am. Chem. Soc. 133, 2525-2534 (2011).

17. Pelaz, B. et al. Diverse applications of nanomedicine. ACS Nano 11, 2313-2381 (2017).

18. Fruijtier-Pölloth, C. The safety of nanostructured synthetic amorphous silica (SAS) as a food additive (E 551). Arch. Toxicol. 90, 2885-2916 (2016).

19. IARC. IARC working group on the evaluation of carcinogenic risks to humans: silica, some silicates, coal dust and para-aramid fibrils. IARC Monogr. Eval. Carcinog. Risks Hum. 68, 1-475 (1997).

20. Sato, T., Shimosato, T. \& Klinman, D. M. Silicosis and lung cancer: current perspectives. Lung Cancer Targets Ther. 9, 91-101 (2018).

21. Borm, P. J. A., Fowler, P. \& Kirkland, D. An updated review of the genotoxicity of respirable crystalline silica. Part. Fibre Toxicol. 15, 23 (2018).

22. Kawasaki, H. A mechanistic review of silica-induced inhalation toxicity. Inhal. Toxicol. 27, 363-377 (2015).

23. Nakayama, M. Macrophage recognition of crystals and nanoparticles. Front. Immunol. 9, 103 (2018).

24. Oberdörster, G. Lung particle overload: implications for occupational exposures to particles. Regul. Toxicol. Pharmacol. 21, 123-135 (1995).

25. Oberdörster, G. Pulmonary effects of inhaled ultrafine particles. Int. Arch. Occup. Environ. Health 74, 1-8 (2001).

26. Shu, F. \& Shi, Y. Systematic overview of solid particles and their host responses. Front. Immunol. 9, 1157 (2018).

27. Chen, L. J. et al. The toxicity of silica nanoparticles to the immune system. Nanomedicine 13, 1939-1962 (2018).

28. Landsiedel, R., Sauer, U. G., Ma-Hock, L., Schnekenburger, J. \& Wiemann, M. Pulmonary toxicity of nanomaterials: a critical comparison of published in vitro assays and in vivo inhalation or instillation studies. Nanomedicine 9, 2557-2585 (2014).

29. Yazdimamaghani, M., Moos, P. J., Dobrovolskaia, M. A. \& Ghandehari, H. Genotoxicity of amorphous silica nanoparticles: Status and prospects. Nanomed. Nanotechnol. Biol. Med. 16, 106-125 (2019).

30. Landsiedel, R. et al. Application of short-term inhalation studies to assess the inhalation toxicity of nanomaterials. Part. Fibre Toxicol. 11, 16 (2014).

31. Skuland, T. et al. Pro-inflammatory effects of crystalline- and nano-sized non-crystalline silica particles in a 3D alveolar model. Part. Fibre Toxicol. 17, 13 (2020).

32. Wiemann, M. et al. An in vitro alveolar macrophage assay for predicting the short-term inhalation toxicity of nanomaterials. J. Nanobiotechnol. 14, 16 (2016).

33. Hsiao, I. L. et al. Size and cell type dependent uptake of silica nanoparticles. J. Nanomed. Nanotechnol. 5, 1000248 (2014).

34. Loza, K. et al. Barium sulfate micro- and nanoparticles as bioinert reference material in particle toxicology. Nanotoxicology 10 , 1492-1502 (2016).

35. Schremmer, I. et al. Kinetics of chemotaxis, cytokine and chemokine release of NR8383 macrophages after exposure to inflammatory and inert granular insoluble particles. Toxicol. Lett. 263, 68-75 (2016).

36. Westphal, G. A. et al. Particle-induced cell migration assay (PICMA): A new in vitro assay for inflammatory particle effects based on permanent cell lines. Toxicol. In Vitro 29, 997-1005 (2015).

37. Stöber, W., Fink, A. \& Bohn, E. Controlled growth of monodisperse silica spheres in the micron size range. J. Colloid Interface Sci. 26, 62-69 (1968).

38. Huang, X. L., Teng, X., Chen, D., Tang, F. Q. \& He, J. Q. The effect of the shape of mesoporous silica nanoparticles on cellular uptake and cell function. Biomaterials 31, 438-448 (2010).

39. Jung, H. S., Moon, D. S. \& Lee, J. K. Quantitative analysis and efficient surface modification of silica nanoparticles. J. Nanomater. 2012, 593471 (2012).

40. Nozawa, K. et al. Smart control of monodisperse Stoeber silica particles: effect of reactant addition rate on growth process. Langmuir 21, 1516-1523 (2005).

41. Bellamy, L. J. The Infra-red Spectra of Complex Molecules (Chapman and Hall, London, 1975).

42. Feliu, N., Sun, X., Alvarez Puebla, R. A. \& Parak, W. J. Quantitative particle-cell interaction: some basic physicochemical pitfalls. Langmuir 33, 6639-6646 (2017).

43. Nazarenus, M. et al. In vitro interaction of colloidal nanoparticles with mammalian cells: What have we learned thus far?. Beilstein J. Nanotechnol. 5, 1477-1490 (2014).

44. Hinderliter, P. M. et al. ISDD: A computational model of particle sedimentation, diffusion and target cell dosimetry for in vitro toxicity studies. Part. Fibre Toxicol. 7, 1-20 (2010).

45. Behzadi, S. et al. Cellular uptake of nanoparticles: journey inside the cell. Chem. Soc. Rev. 46, 4218-4244 (2017).

46. Greulich, C. et al. Uptake and intracellular distribution of silver nanoparticles in human mesenchymal stem cells. Acta Biomater. 7, 347-354 (2011).

47. Beddoes, C. M., Case, C. P. \& Briscoe, W. H. Understanding nanoparticle cellular entry: a physicochemical perspective. Adv. Coll. Interface Sci. 218, 48-68 (2015).

48. Kuhn, D. A. et al. Different endocytotic uptake mechanisms for nanoparticles in epithelial cells and macrophages. Beilstein J. Nanotechnol. 5, 1625-1636 (2014).

49. Dykman, L. A. \& Khlebtsov, N. G. Uptake of engineered gold nanoparticles into mammalian cells. Chem. Rev. 114, 1258-1288 (2014).

50. Iversen, T. G., Skotland, T. \& Sandvig, K. Endocytosis and intracellular transport of nanoparticles: present knowledge and need for future studies. Nano Today 6, 176-185 (2011). 
51. Sahay, G., Alakhova, D. Y. \& Kabanov, A. V. Endocytosis of nanomedicines. J. Control. Release 145, 182-195 (2010).

52. Gil, P. R., Nazarenus, M., Ashraf, S. \& Parak, W. J. pH-sensitive capsules as intracellular optical reporters for monitoring lysosomal pH changes upon stimulation. Small 8, 943-948 (2012).

53. Messerschmidt, C. et al. On the pathway of cellular uptake: new insight into the interaction between the cell membrane and very small nanoparticles. Beilstein J. Nanotechnol. 7, 1296-1311 (2016).

54. Herd, H. et al. Nanoparticle geometry and surface orientation influence mode of cellular uptake. ACS Nano 7, 1961-1973 (2013).

55. Sokolova, V. et al. A systematic electron microscopic study on the uptake of barium sulphate nano-, submicro-, microparticles by bone marrow-derived phagocytosing cells. Acta Biomater. 80, 352-363 (2018).

56. Patel, S. et al. Brief update on endocytosis of nanomedicines. Adv. Drug Deliv. Rev. 144, 90-111 (2019).

57. Kollenda, S. et al. A pH-sensitive fluorescent protein sensor to follow the pathway of calcium phosphate nanoparticles into cells. Acta Biomater. 111, 406-417 (2020).

58. Duhamel, M. et al. Molecular consequences of proprotein convertase 1/3 (PC1/3) inhibition in macrophages for application to cancer immunotherapy: A proteomic study. Mol. Cell. Proteom. 14, 2857-2877 (2015).

59. Waters, K. M. et al. Macrophage responses to silica nanoparticles are highly conserved across particle sizes. Toxicol. Sci. 107, 553-569 (2009).

60. Pauluhn, J. Poorly soluble particulates: searching for a unifying denominator of nanoparticles and fine particles for DNEL estimation. Toxicology 279, 176-188 (2011).

61. Pauluhn, J. Derivation of occupational exposure levels (OELs) of low-toxicity isometric biopersistent particles: how can the kinetic lung overload paradigm be used for improved inhalation toxicity study design and OEL-derivation?. Part. Fibre Toxicol. 11, 72 (2014).

62. Li, Y. \& Boraschi, D. Endotoxin contamination: a key element in the interpretation of nanosafety studies. Nanomedicine 11, 269-287 (2016).

63. Yu, T., Malugin, A. \& Ghandehari, H. Impact of silica nanoparticle design on cellular toxicity and hemolytic activity. ACS Nano 5, 5717-5728 (2011)

64. Breitman, T. R., Selonick, S. E. \& Collins, S. J. Induction of differentiation of the human promyelocytic leukemia cell line (HL-60) by retinoic acid. Proc. Natl. Acad. Sci. USA 77, 2936-2940 (1980).

65. Boyden, S. The chemotactic effect of mixtures of antibody and antigen on polymorphonuclear leucocytes. J. Exp. Med. 115, 453-466 (1962).

\section{Acknowledgements}

The use of FIB for the preparation of cross-sectional images at ZGH, RUB, is acknowledged.

\section{Author contributions}

M.K., M.O., N.R., K.L., M.B., A.R., and N.Z. performed the experiments, and contributed to experimental planning and design in collaboration with G.W., J.B., A.L., M.K., C.S., and M.E. M.K., M.O., N.R., K.L., M.B., A.R., and N.Z. performed the data analysis and statistics. G.W., J.B., M.K., C.S., and M.E. wrote the manuscript in collaboration with the other authors. All authors read and approved the final manuscript.

\section{Funding}

Open Access funding enabled and organized by Projekt DEAL. The authors acknowledge financial support of this work by the Deutsche Gesetzliche Unfallversicherung (DGUV, Project FP 412).

\section{Competing interests}

The authors declare no competing interests.

\section{Additional information}

Correspondence and requests for materials should be addressed to C.S. or M.E.

Reprints and permissions information is available at www.nature.com/reprints.

Publisher's note Springer Nature remains neutral with regard to jurisdictional claims in published maps and institutional affiliations.

(c) (i) Open Access This article is licensed under a Creative Commons Attribution 4.0 International License, which permits use, sharing, adaptation, distribution and reproduction in any medium or format, as long as you give appropriate credit to the original author(s) and the source, provide a link to the Creative Commons licence, and indicate if changes were made. The images or other third party material in this article are included in the article's Creative Commons licence, unless indicated otherwise in a credit line to the material. If material is not included in the article's Creative Commons licence and your intended use is not permitted by statutory regulation or exceeds the permitted use, you will need to obtain permission directly from the copyright holder. To view a copy of this licence, visit http://creativecommons.org/licenses/by/4.0/.

(C) The Author(s) 2020 